\title{
丰产金属催化烯基金属试剂的不对称烯基化反应研究进展
}

\author{
吴良 ${ }^{a}$ 魏瀚林 $a$ 申杰峰*, $a$ 陈建中 $*, b$ 张万斌 $a, b$ \\ ( ${ }^{a}$ 上海交通大学药学院 变革性分子前沿科学中心 上海市手性药物分子工程重点实验室 上海 200240) \\ $\left({ }^{b}\right.$ 上海交通大学化学化工学院 上海 200240)
}

\begin{abstract}
摘要 烯丙位手性中心不仅广泛存在于天然产物和药物活性分子中，也是有机合成中的重要合成砌块. 过渡金属催化 烯基金属试剂作为亲核试剂的不对称加成或偶联反应是构建这一结构非常有吸引力的策略之一. 在众多金属催化剂 中, 铁钴镍铜等丰产金属由于其独特的催化活性以及低毒性、环境友好等优点而被用来代替铑钯等稀有金属应用于此 类不对称烯基化反应中, 并取得了显著的成果. 基于此, 本文将综述丰产金属催化的烯基金属试剂参与的不对称烯基 化反应研究进展. 主要包括: (1)钴催化的不对称烯基化反应, (2)镍催化的不对称烯基化反应, (3)铜催化的不对称烯基 化反应以及(4)其他丰产金属催化的不对称烯基化反应等四部分.
\end{abstract}

关键词 丰产金属催化; 烯基金属试剂; 不对称烯基化; 不对称加成; 不对称偶联

\section{Development of Earth-Abundant Metals-Catalyzed Enantioselective Alkenylations Using Alkenyl Metal Reagents}

\author{
Liang $\mathrm{Wu}^{a} \quad{\text { Hanlin } \mathrm{Wei}^{a} \quad \text { Jiefeng Shen }}^{*, a} \quad$ Jianzhong Chen ${ }^{*, b} \quad$ Wanbin Zhang ${ }^{a, b}$ \\ ( ${ }^{a}$ Shanghai Key Laboratory for Molecular Engineering and Chiral Drugs, Frontiers Science Center for \\ Transformative Molecules, School of Pharmacy, Shanghai Jiao Tong University, Shanghai 200240, China) \\ ( ${ }^{b}$ School of Chemistry and Chemical Engineering, Shanghai Jiao Tong University, Shanghai 200240, China)
}

\begin{abstract}
Allylic chiral centers are widely present in natural products and pharmaceutically active molecules, and play a vital role in the construction of organic compounds through pericyclic reactions, oxidations or reductions and other transformations. The transition metal-catalyzed asymmetric addition or coupling reaction using alkenyl metal nucleophiles is one of the most attractive strategies for the synthesis of these structures. Among the many metal catalysts, earth-abundant transition metals such as iron, cobalt, nickel and copper have been used to replace precious metals such as rhodium and palladium, and have gained attention for use in enantioselective alkenylations. Indeed, remarkable advances have been achieved with these catalysts due to their unique catalytic activity, low toxicity and environmentally friendliness. The earth-abundant transition metals are known to undergo facile one electron oxidation state changes. In the reaction process, the earth-abundant transition metals have the ability to undergo two-electron transfer and single-electron transfer processes, therefore they have more valence changes and catalytic pathways which can be exploited. Based on this, this article will review the latest research in earth-abundant metal-catalyzed enantioselective alkenylation using alkenyl metal reagents. It is divided into four sections consisting of cobalt-catalyzed enantioselective alkenylations using alkenyl metal reagents, nickel-catalyzed enantioselective alkenylations using alkenyl metal reagents, copper-catalyzed enantioselective alkenylations using alkenyl metal reagents, and other earth-abundant transition metals catalyzed enantioselective alkenylations using alkenyl metal reagents.
\end{abstract}

Keywords earth-abundant metal catalysis; alkenyl metal reagent; enantioselective alkenylation; asymmetric addition; asymmetric coupling

\section{1 引言}

第一周期过渡系金属元素在地壳中含量丰富, 特别 是铁钴镍铜等后过渡金属，也可称之为丰产金属，几乎 是无限量供应. 近年来, 丰产金属催化的有机反应引起 了全球有机化学家的广泛关注与研究, 开始应用于如不 对称加成、不对称催化氢化、偶联、 $\mathrm{C}-\mathrm{H}$ 活化等反应 中 ${ }^{[1-4]}$. 相比于钓铑钯铱等稀有金属, 铁钴镍铜等丰产金
属还具有低毒、环境友好等优点. 最重要的是丰产金属 在催化反应中往往表现出与稀有金属不同的催化特性. 例如, 由于丰产金属的原子半径相比于稀有金属较小, 负电性较低, 更易发生氧化加成, 并且在反应过程中得 到有机金属中间体 $\mathrm{C}-\mathrm{M}(\mathrm{M}=\mathrm{Fe} 、 \mathrm{Co} 、 \mathrm{Ni} 、 \mathrm{Cu}$ 等)不易 发生 $\beta-\mathrm{H}$ 消除, 从而减少了副反应的发生. 同时, 在反 应中钉铑钯铱等稀有金属通常只能发生双电子转移过

*E-mail: sjfhx@163.com; 0091109001@sju.edu.cn

Received July 20, 2021; published September 17, 2021.

Project supported by the Shanghai Post-Doctoral Excellence Program (No. 2020272), and National Natural Science Foundation of China (Nos. 21620102003, 21772119, 21831005).

上海市“超级博士后”激励计划(No. 2020272)和国家自然科学基金(Nos. 21620102003, 21772119, 21831005)资助项目. 
程, 而铁钴镍铜等丰产金属能够在发生双电子转移的同 时通常还具备单电子转移的能力, 因此在反应中它们有 更多价态的变化. 例如, 目前已经分离鉴定的镍化合物 价态包括 $\mathrm{Ni}^{0} 、 \mathrm{Ni}^{\mathrm{I}} 、 \mathrm{Ni}^{\mathrm{II}} 、 \mathrm{Ni}^{\mathrm{III}} 、 \mathrm{Ni}^{\mathrm{IV}}$, 使得其在催化反应 过程中, 既可能存在 $\mathrm{Ni}^{0} / \mathrm{Ni}^{\mathrm{II}}$ 的双电子催化机理, 也可能 存在涉及到自由基的 $\mathrm{Ni}^{\mathrm{I}} / \mathrm{Ni}^{\mathrm{II}} / \mathrm{Ni}^{\mathrm{III}}$ 单电子催化机理. 这 也为开发全新的反应类型和探索新的催化循环机理, 尤 其是为解决稀有金属催化剂中存在的难题提供了更多 的可能与手段. 所以发展合适的体系来实现丰产金属催 化的不对称反应是一项非常重要的工作, 可以降低催化 剂成本，有利于反应的工业化应用.

烯烃化合物作为反应原料，通过周环反应、聚合、 氧化或还原等反应在有机物的构建中起着至关重要的 作用. 烯丙位手性结构广泛存在于许多天然产物和药物 活性分子中, 由于双键易于官能团化便于进行下一步的 转化和改造, 更加受到有机化学家的关注与研究 ${ }^{[5]}$. 通 过过渡金属催化的烯基金属试剂作为亲核试剂的不对 称加成或偶联反应是一类构建这一结构的非常有吸引 力的策略, 因为该方法在引入烯烃双键结构的同时也构 建了手性中心. 目前能够实现此类不对称烯基化反应主 要集中于铑、钯等稀有金属催化剂, 相关理论和机理研 究也得到了充分的发展. 但是这些稀有过渡金属催化剂 面临着地球储量有限、价格昂贵和重金属污染环境等问 题. 因而发展地球储量丰富、价格低廉且对环境友好的, 符合现代化学可持续发展要求的铁钴镍铜的不对称催 化体系显得尤为重要(图 1).

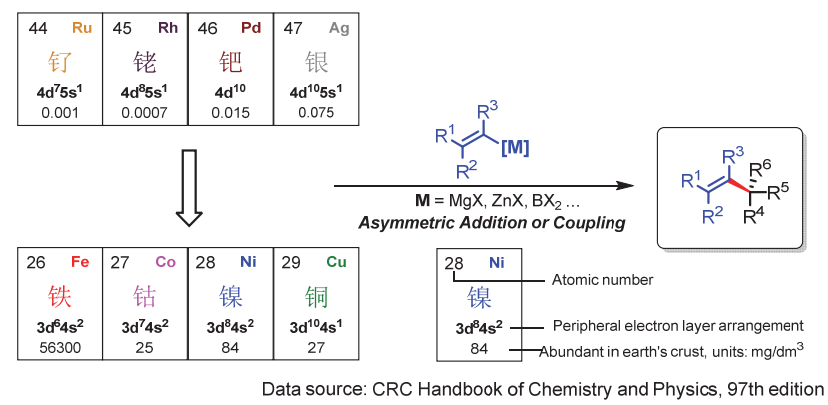

图 1 丰产金属催化的烯基金属试剂作为亲核试剂的不对称烯基化反 应

Figure 1 Earth-abundant metals-catalyzed enantioselective alkenylation using alkenyl metal nucleophiles

在近十几年里, 铁钴镍铜等丰产金属催化的烯基金 属试剂作为亲核试剂的不对称烯基化反应已经成为高 效构建烯丙位手性中心的有效方法之一, 并且在天然产 物、药物合成中得到了应用. 本文将从(1)钴催化的不对 称烯基化反应，(2)镍催化的不对称烯基化反应，(3)铜催 化的不对称烯基化反应以及(4)其他丰产金属催化的不 对称烯基化反应等方面进行阐述和总结.

\section{2 钴催化的不对称烯基化反应}

\section{1 钴催化的不对称加成反应}

碳氧不饱和双键的不对称烯基化反应是合成手性 烯丙醇的重要方法之一 ${ }^{[6]}$. 手性烯丙醇是一类重要的合 成砌块，是用于精制聚乙酸酯和丙酸酯的结构单元，并 且广泛存在于天然产物和药物活性分子中(图 2) ${ }^{[7]}$. 它们 可以通过各种选择性转化, 得到一系列重要的手性化合 物. 此外, 这类化合物也是用于手性配体设计的重要骨 架结构. 所以近几十年来，过渡金属特别是丰产金属催 化的碳氧双键的不对称烯基化反应一直是有机化学领 域研究的方向之一. 有机金属试剂主要包括有机镁试剂 $(\mathrm{RMgX})$, 有机锌试剂 $(\mathrm{RZnX})$, 有机嗍试剂 $\left.\left(\mathrm{RB}(\mathrm{OR})^{\prime}\right)_{2}\right)$ 等. 有机嗍酸试剂较其它金属有机试剂, 具有对空气和 水稳定, 操作存储简便, 反应时官能团耐受性好等优点, 因此有机嗍酸参与的钴催化的不对称烯基化反应得到 了广泛的关注.

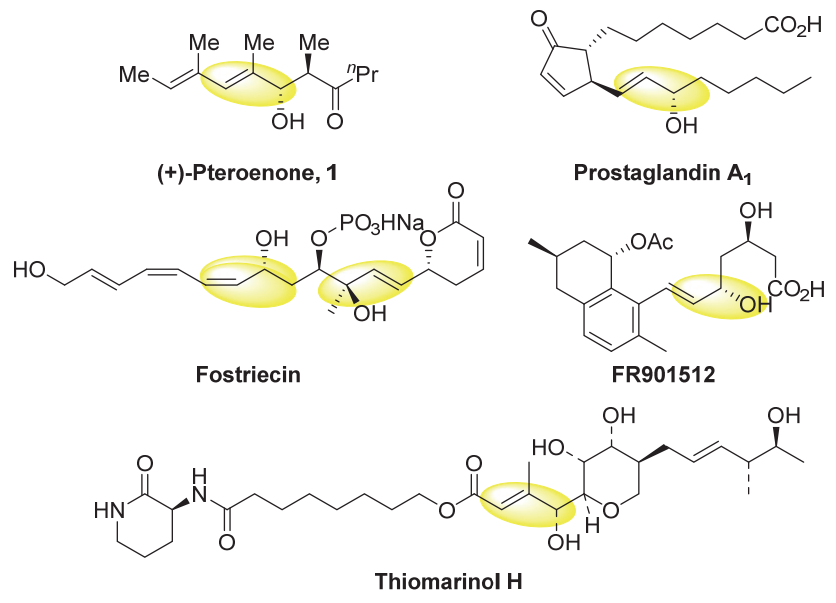

图 2 手性烯丙醇类化合物

Figure 2 Chiral allyl alcohols

2016 年, 赵宇课题组 ${ }^{[8]}$ 实现了钴催化的 $\alpha$-酮酸酯、 氧化吲哚以及环状醛亚胺的不对称烯基化反应, 并以优 异的对映选择性得到叔烯丙醇以及 $\alpha$-仲烯丙胺类衍生 物. 反应中使用了商业可得的催化剂和试剂, 具有高度 的实用性. 这一合成方法具有效率高、选择性优异、操 作简便、底物普遍性好等优点. 拓展了钴作为催化剂在 不对称合成中的应用范围(图 3).

2019 年, 孟繁柯课题组 ${ }^{[9]}$ 开发了一例钴催化的 3,3二取代环丙烯与烯基硼酸的不对称加成反应，最高获得 95\%的收率，98\%的对映选择性以及大于 $20: 1$ 的非对 映选择性. 反应中使用的钴催化剂、手性配体商业可得, 通过这一方法可以高效地合成手性环丙烷类衍生物，这 是一类生物活性分子中重要的骨架结构. 在标准条件下 进行不对称烯基化反应后，经过简单的水解，能够以 $54 \%$ 的总收率，94\%的对映选择性得到类视黄醇 X 受体 激动剂 AGN194204 的类似物. 值得注意的是, 该反应 在机理上质子很可能完全来自于烯基嗍酸, 而非外界引 
入质子源(图 4).

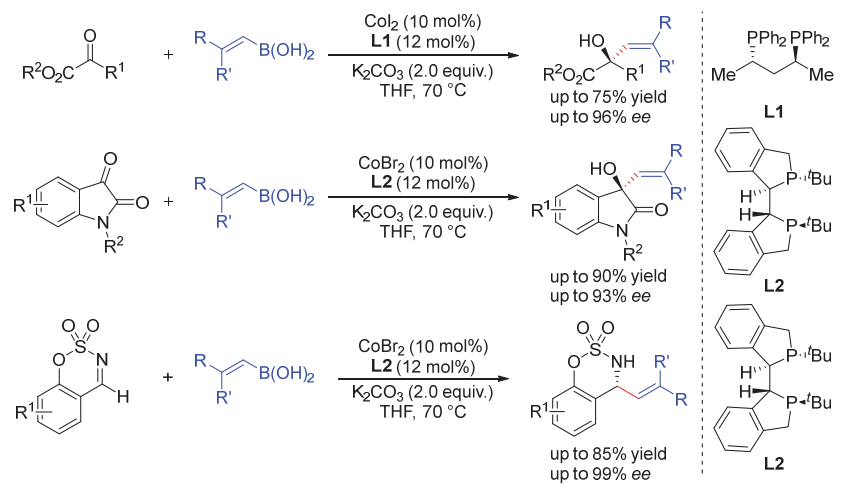

图 3 钴催化酮和亚胺的不对称烯基化反应

Figure 3 Co-catalyzed asymmetric alkenylation of ketones and imines

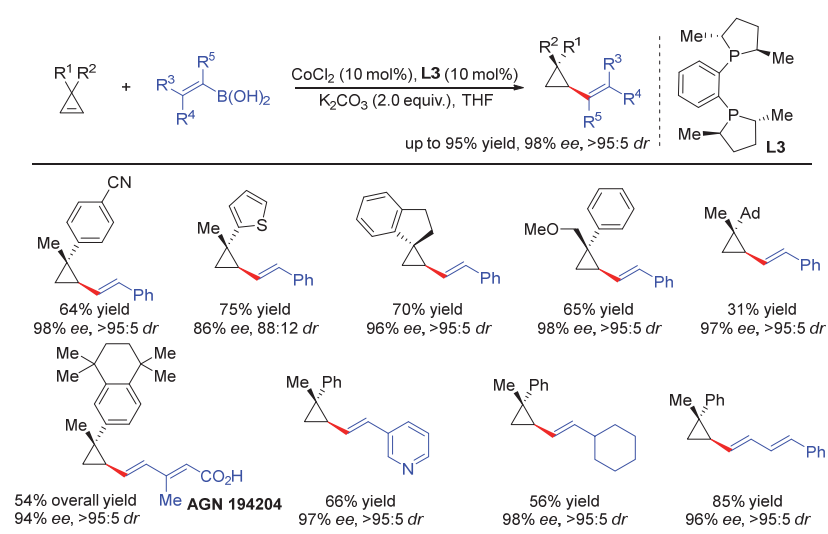

图 4 钴催化环丙烯的不对称烯基化反应

Figure 4 Co-catalyzed asymmetric alkenylation of cyclopropenes

\section{2 钴催化的不对称偶联反应}

过渡金属催化的交叉偶联反应同样是构建碳-碳键 最强大的策略之一. 过去几十年间，烷基或者芳基卤化 物参与的交叉偶联反应领域已经取得了许多重大的进 展. 特别是丰产金属催化的烯基金属试剂作为亲核试剂 的不对称偶联反应作为基本的转化之一, 得到了越来越 多的研究, 也取得了一定的进展. 2020 年, 钟江春课题 组 ${ }^{[10]}$ 报道了一例钴/双噁唑啉体系催化的有机卤化物与 烯基镁试剂的不对称交叉偶联反应, 以中等至良好的收 率和优异的对映选择性得到 $\alpha$-烷基- $\beta, \gamma$-不饱和酯类化合 物. 初步的机理研究表明, 这一不对称烯基化主要通过 自由基中间体发生. 此外, 此类不对称 Kumada 烯基化 可应用于 California 红鳞信息素的高效合成(图 5).

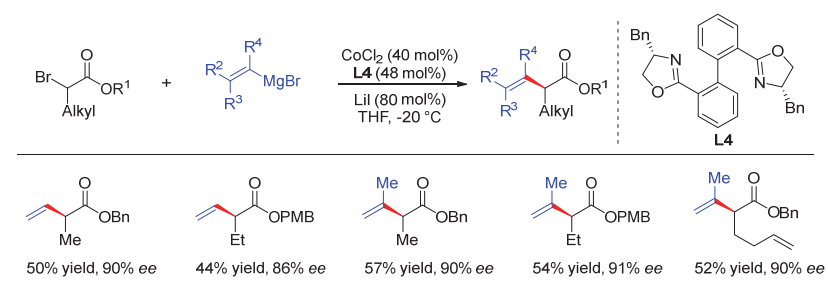

图 5 钴催化 $\alpha$-溴代酯与烯基镁试剂的不对称偶联反应

Figure 5 Co-catalyzed asymmetric coupling of $\alpha$-bromo esters with alkenyl magnesium reagents

\section{3 镍催化的不对称烯基化反应}

\section{1 镍催化的不对称加成反应}

手性烯丙胺结构普遍存在于天然产物和生物活性 分子中(图 6), 并且这一结构往往决定着该分子的稳定 性、生物和药物活性等 ${ }^{[11]}$. 由于其巨大的作用，这一骨 架结构的构建逐渐成为化学工作者关注的重要领域之

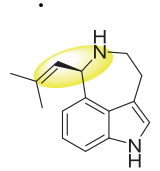

(-)-Aurantioclavin

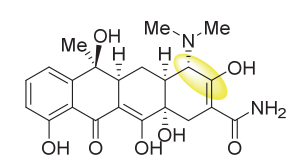

(-)-Tetracycline

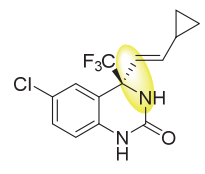

DPC 083
图 6 手性烯丙胺类化合物

Figure 6 Chiral allyl amines

近年来以丰产金属镍为催化剂，通过烯基喼试剂对 碳氮不饱和双键的不对称加成反应，从而获得大量的手 性胺产物的策略得到了关注与研究. 张万斌课题组在这 一领域中做出了许多系统性的工作. 2018 年, 该小组 ${ }^{[12]}$ 以其自主研发的单边二茂钉膦噁唑啉 L5 为手性配体, 高效地催化了环状醛亚胺与烯基嗍酸的不对称加成反 应. 在最优的反应条件下，一系列的环状醛亚胺及烯基 硼酸都能顺利地进行反应，并且最高获得 $99 \%$ 的对映选 择性(图 7). 该研究的特色在于反应处在一个敞开的体 系，耐水耐空气，操作简单.

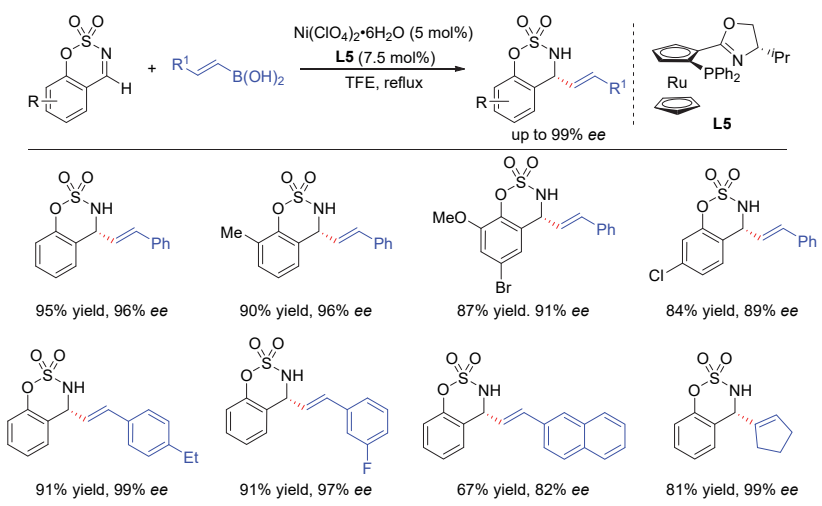

图 7 镍催化环状醛亚胺与烯基硼试剂的不对称加成反应

Figure 7 Ni-catalyzed asymmetric addition of cyclic aldimines with alkenyl boron reagents

同年，该小组又报道了以三氟甲磺酸镍 $\left(\mathrm{Ni}(\mathrm{OTf})_{2}\right)$ 为镍催化剂, 手性双噁唑啉 L6 为配体, 采用一系列烯 基取代的苯并磺酰亚胺作为底物, 高效地实现了镍催化 烯基嗍酸对酮亚胺的不对称加成/扩环串联反应，最高 获得 $99 \%$ 的收率以及大于 $99 \%$ 的对映选择性 ${ }^{[13]}$. 该反应 条件温和, 操作简便, 可在试管中敞口反应. 在克级规 模下仍然可以得到优异的结果, 具有较好的实用价值. 当使用共轭氮杂双烯作为底物时, 通过串联的加成/扩 环反应，能够实现苯并七元环手性磺酰胺类产物的一步 合成(图 8). 


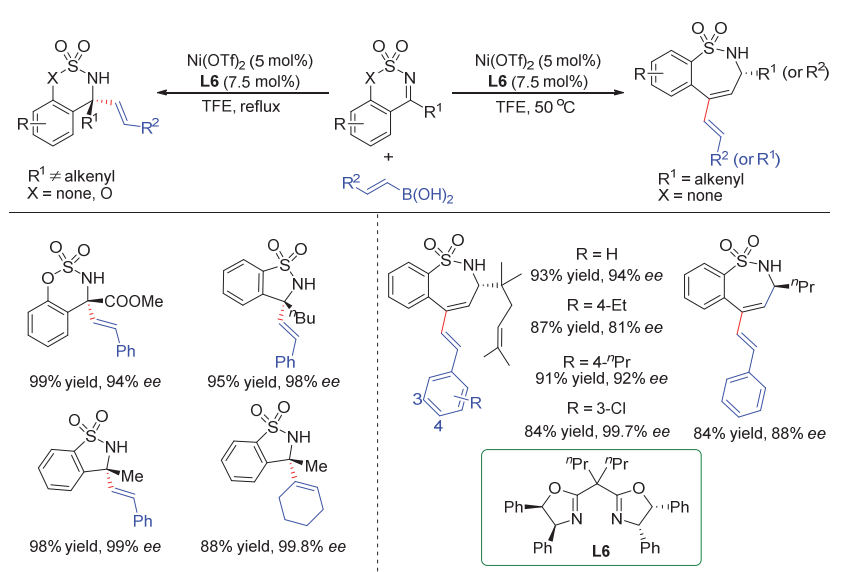

图 8 镍催化环状酮亚胺与烯基硼试剂的不对称加成反应

Figure 8 Ni-catalyzed asymmetric addition of cyclic ketimines with alkenyl boron reagents

在对反应机理进一步研究后发现该反应由两个步 骤串联而成, 其中第一步的烯基化步骤是产生手性的决 定步骤, 需要通过镍金属催化来完成, 扩环步骤是一个 立体专一性过程, 能够很好地实现手性保持. 具体而言, 酮亚胺底物在镍-配体的催化下生成烯基加成中间体 1 . 中间体 1 形成后立刻被酸(Ni(II)或烯基硼酸)活化导致 $\mathrm{C}-\mathrm{N}$ 键消除形成碳阳离子中间体. 当使用烷基-烯基取 代的酮亚胺和苯乙烯型的硼酸时 $\left(\mathrm{R}^{1}=\mathrm{alkyl}, \mathrm{R}^{2}=\mathrm{aryl}\right)$, 会产生阳离子模型 $\mathbf{A}$. 当使用芳基-乙烯基取代的酮亚 胺和烷基-乙烯基取代的嗍酸时 $\left(\mathrm{R}^{1}=\operatorname{aryl}, \mathrm{R}^{2}=\mathrm{alkyl}\right)$, 会 形成阳离子模型 $\mathbf{B}$. 在模型 $\mathbf{A}$ 和模型 $\mathbf{B}$ 中, 磺酰胺阴离 子进攻烷基取代的碳-碳双键, 分别形成大 $\pi$-共轭的环 状产物 2 和 3 并且构型相反. 当 $R^{1}$ 是叔丁基而 $\mathrm{R}^{2}$ 是正 丙基时, 磺酰胺阴离子进攻位阻小的碳原子形成模型 $\mathbf{C}$ 从而得到产物 4. 磺酰基取代的苯环通过单键旋转而导 致 $e e$ 值降低的现象在该反应中未发生. 由实验结果可 以看出, 该反应更倾向于形成大 $\pi$-共轭的产物(图 9).

2019 年, 周其林课题组 ${ }^{[14]}$ 以双(1,5-环辛二烯)镍 $\left(\mathrm{Ni}(\mathrm{cod})_{2}\right)$ 和手性螺环膦氮配体 $\mathbf{L} 7$ 体系实现了苯乙烯类 底物与烯基嗍酸的对映选择性烯基化反应, 该反应条件 简单温和、原子经济, 环境友好, 能够一步合成光学纯 的 1,1-二芳基烷烃类化合物. 它们是许多具有生物活性 化合物的基本结构单元. 该小组进行的気代实验结果表 明, 反应中 $\mathrm{Ni}-\mathrm{H}$ 物种的氢源来源于醇溶剂的 $\mathrm{O}-\mathrm{H}$ 氢 原子而不是 $\mathrm{C}-\mathrm{H}$ 氢原子(图 10).

几乎在同一时期, 梅天胜课题组 ${ }^{[15]}$ 同样报道了镍 催化的苯乙烯与烯基硼酸的不对称烯基化反应. 该反应 中以双噁唑啉 $\mathbf{L 8}$ 为手性配体, $\mathrm{MeOH}$ 作为氢源, 最高能 够获得 96\%的对映选择性. 并且利用该方法高效实现了

(R)-Ibuprofen 的合成(图 11).

2021 年, 施世良课题组 ${ }^{[16]}$ 报道了一例镍催化酫与 烯基嗍酸酯的不对称加成反应. 高收率和高对映选择性 地得到各种手性仲醇化合物(up to $91 \% e e$ ), 底物范围广

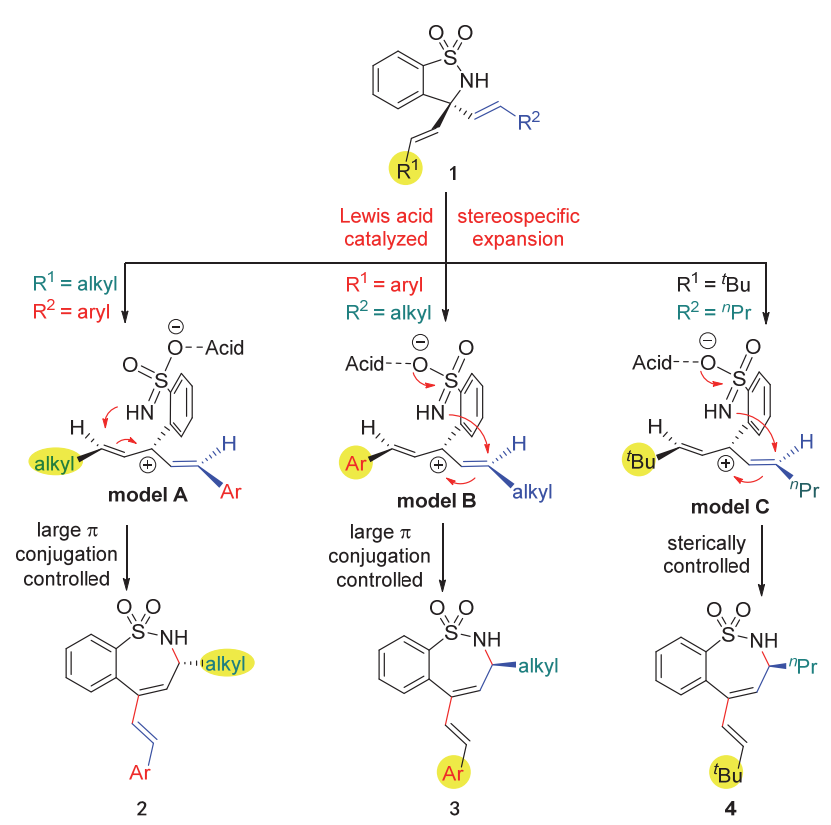

图 9 扩环步骤可能的机理

Figure 9 Proposed mechanism for ring-expansion step

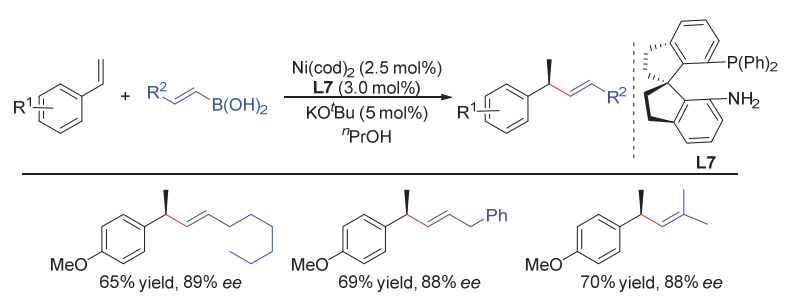

图 10 镍/螺环膦氮催化苯乙烯的不对称烯基化反应

Figure $10 \mathrm{Ni} /$ Spiro aminophosphine catalyzed asymmetric alkenylation of styrenes

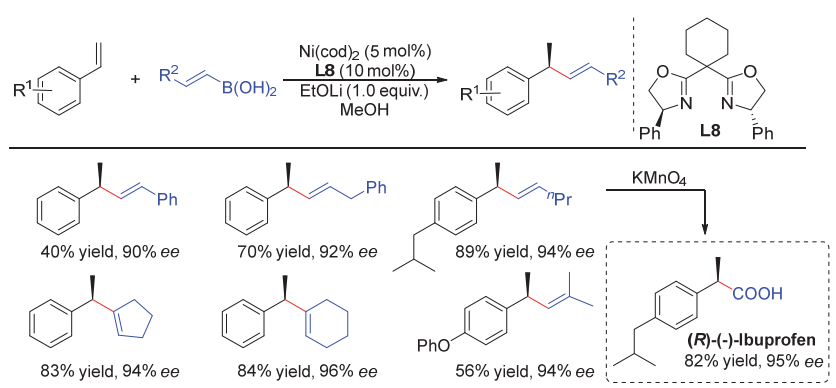

图 11 镍/双噁唑啉催化苯乙烯的不对称烯基化反应

Figure $11 \mathrm{Ni} / \mathrm{BOX}$ catalyzed asymmetric alkenylation of styrenes

泛，官能团耐受性优异. 根据文献和相关的实验结果， 该小组提出了可能的反应机理：首先富电子的手性 $\mathrm{NHC}$ 配体与 $\mathrm{Ni}^{0}$ 配位, 从而促进了立体选择性的 $\eta^{2}$-配 位和氧化环化形成氧镍三元环中间体. 随后 CsF 促进了 其与有机嗍酸酯的转金属化过程，得到 $\mathrm{Ni}$-烷基物种. 最后还原消除获得手性仲醇类化合物，同时释放出 $\mathrm{Ni}^{0}$ 催化剂. 值得注意的是，在这一反应中通过反应条件的 篮选避免了 Aldol 反应以及其他三个副反应：通过 Tishchenko 形成酯的反应，仲醇脱氢形成酮的反应，以 及醛类化合物的加氢反应(图 12). 


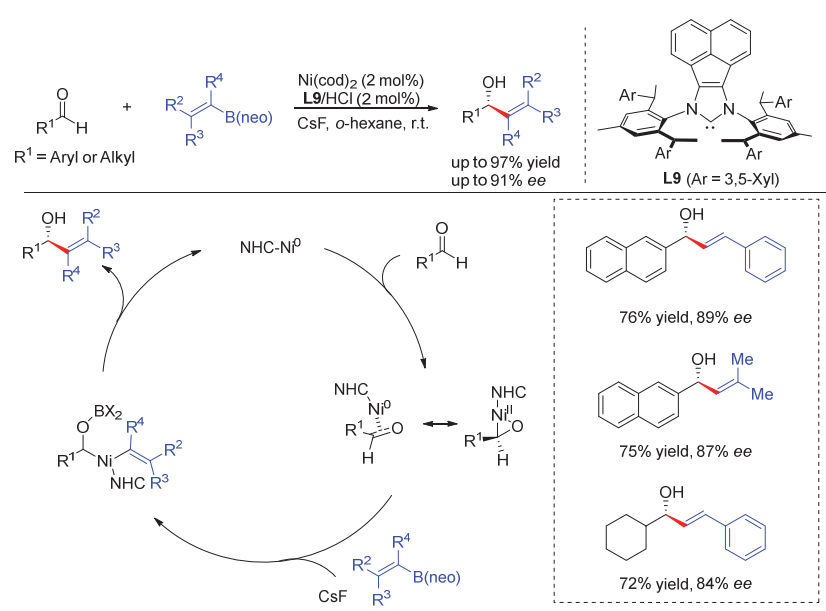

图 12 镍催化醛与烯基嗍试剂的不对称加成反应及机理

Figure 12 Ni-catalyzed asymmetric addition of aldehydes with alkenyl boron reagents and mechanism

\section{2 镍催化的不对称偶联反应}

2008 年, $\mathrm{Fu}$ 课题组 ${ }^{[17]}$ 报道了镍催化的外消旋 $\alpha$-溴 代酯与烯基硅试剂的不对称交叉偶联反应，以良好的对 映选择性得到具有重要合成价值的 $\alpha$-烯基羧酸类衍生 物，最高获得 $93 \%$ 的 ee 值(图 13).

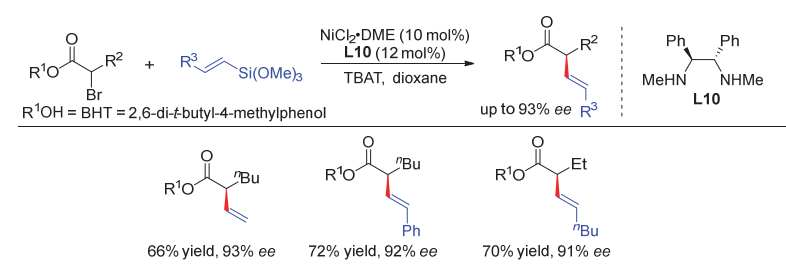

图 13 镍催化 $\alpha$-溴代酯与烯基硅试剂的不对称偶联反应

Figure 13 Ni-catalyzed asymmetric coupling of $\alpha$-bromo esters with alkenyl silicon reagents

2010 年, 该小组使用烯基锆试剂为亲核试剂, 镍为 催化剂，实现了其与 $\alpha$-卤代酮的不对称交叉偶联反 应 ${ }^{[18]}$. 外消旋的 $\alpha$-卤代酮通过手性汇聚过程, 高收率和 高对映选择性地合成了 $\beta, \gamma$-不饱和酮类化合物, 反应条 件简单温和, 无需外加添加剂. 产物通过简单的四氢铝 锂还原，能够得到高烯丙醇类衍生物(图 14).

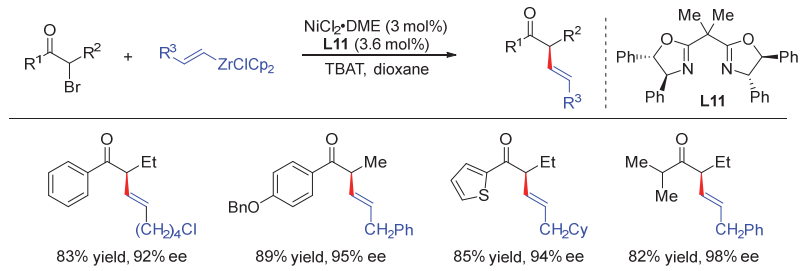

图 14 镍催化 $\alpha$-溴代酯与烯基锆试剂的不对称偶联反应

Figure 14 Ni-catalyzed asymmetric coupling of $\alpha$-bromo esters with alkenyl zirconium reagents

2012 年, Fu 课题组 ${ }^{[19]}$ 又将烯基金属试剂的范围拓 展到了烯基锌试剂, 实现了其与外消旋 $\alpha$-卤代腈的不对 称交叉偶联反应, 通过手性汇聚过程得到光学纯的 $\alpha$-烯 丙基腈类化合物. 该反应能够在 $-78{ }^{\circ} \mathrm{C}$ 下进行, 得到 优异的收率和对映选择性控制, 是迄今为止报道的此类
不对称反应构建碳-碳键的最低温度形成过程(图 15).

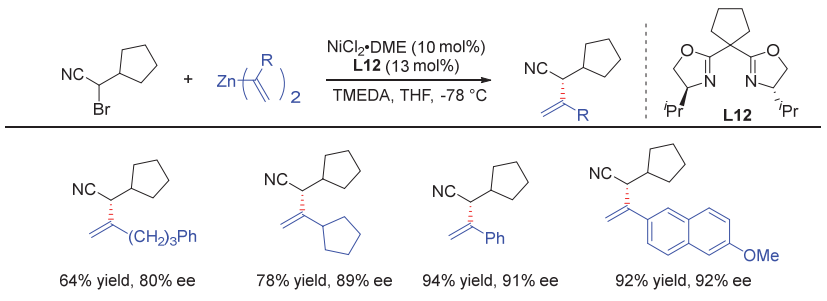

图 15 镍催化 $\alpha$-溴代腈与烯基锌试剂的不对称偶联反应

Figure 15 Ni-catalyzed asymmetric coupling of $\alpha$-bromonitriles with alkenyl zinc reagents

高效合成光学纯的磺酰胺和砜是有机合成、药物化 学等领域的重要目标 ${ }^{[20]}$. 然而, 到目前为止通过不对称 催化的方法直接构建此类含硫碳手性中心仍鲜有报道. 2014 年, $\mathrm{Fu}$ 课题组 ${ }^{[21]}$ 开发了一例镍催化的外消旋 $\alpha$-溴 磺酰胺以及 $\alpha$-溴砜与烯基锆试剂的手性汇聚不对称偶 联反应，以优异的收率和对映选择性得到所需的烯基化 产物. 机理研究表明, 在反应过程中产生了自由基中间 体，并且该自由基具有足够的寿命以扩散出溶剂笼并环 化到侧链烯烃上，从而促进反应的进行(图 16).

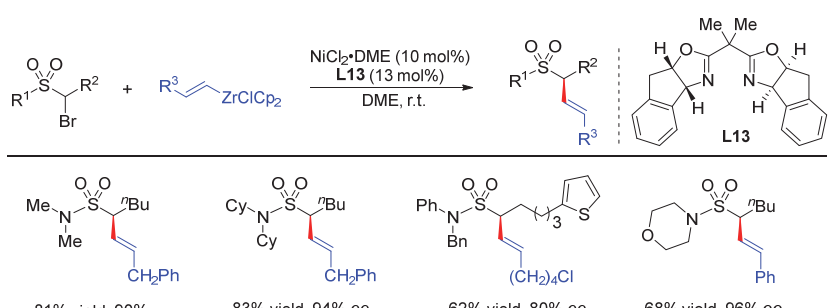

$81 \%$ yield, $90 \%$ ee $\quad 83 \%$ yield, $94 \%$ ee $\quad 62 \%$ yield, $80 \%$ ee $\quad 68 \%$ yield, $96 \%$ ee

图 16 镍催化 $\alpha$-溴磺酰胺等与烯基锆试剂的不对称偶联反应

Figure 16 Ni-catalyzed asymmetric coupling of $\alpha$-bromosulfonamides with alkenyl zirconium reagents

手性汇聚的偶联反应能够将外消旋体直接高收率 和高对映选择性地转化为目标产物, 从而弥补了立体专 一性偶联和动力学拆分的不足. 近几年来通过镍催化外 消旋烷基亲电试剂参与的手性汇聚不对称偶联反应来 构建手性中心的策略得到了越来越多的研究. 通常情况 下，用于镍催化的不对称偶联反应的烷基亲电试剂仅限 于可产生手性叔碳立体中心的卤化物或类似物的仲烷 基亲电试剂, 如上述的 $\mathrm{Fu}$ 实现的几个例子. 而大位阻叔 烷基亲电试剂参与的不对称偶联反应来构筑季碳手性 中心却鲜有报道. 2018 年, Fu 课题组发表了一例镍不对 称催化偶联反应构筑手性季碳的研究工作 ${ }^{[22]}$. 几乎与 此同时, 张万斌课题组 ${ }^{[23]}$ 报道了镍催化的叔醇衍生物 为亲电试剂构建季碳手性中心的不对称偶联反应, 通过 镍/双膦体系催化了螺环环氧吲哚酮与烯基嗍酸的不对 称开环偶联烯基化反应, 外消旋的螺环环氧吲哚酮原料 通过手性汇聚过程, 高收率和高对映选择性地合成了含 有季碳立体中心的手性高烯丙醇类化合物。该反应提供 了镍催化的叔烷基亲电试剂参与的对映选择性交叉偶 联反应和外消旋环氧化物的手性汇聚转化的罕见实例. 
最后结合自由基捕获实验以及相关的立体化学实验，该 小组更倾向于在氧化加成过程中生成稳定的叔碳自由 基中间体的单电子转移机理, 从而实现对映选择性的控 制. 首先镍对螺环环氧吲哚酮进行反应, 得到叔烷基亲 电自由基 5 , 镍的价态升高一价. 随后手性镍与自由基 碳键合从而诱导出手性中间体 $\mathbf{6}$, 镍的价态再升高一价. 然后与烯基喼酸进行转金属化, 得到中间体 7. 最后还 原消除得到开环烯基化产物, 镍的价态降低二价, 进入 下一个催化循环. 另一种可能是先进行转金属化, 然后 发生氧化加成(图 17).
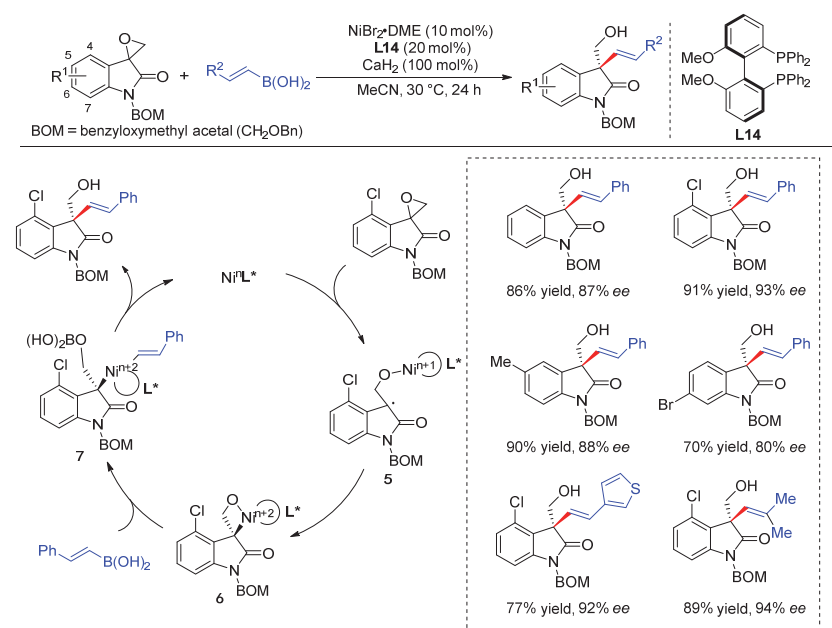

图 17 镍催化螺环环氧吲哚酮与烯基硼酸的不对称偶联反应及机理 Figure 17 Ni-catalyzed asymmetric coupling of spiro-epoxyoxindoles with alkenylboronic acids and mechanism

随后, Fu 课题组 ${ }^{[24]}$ 报道了镍催化的外消旋三级卤代 物与烯基锆试剂的不对称偶联反应，高效地构筑了羰基 $\alpha$ 位手性季碳中心. 该反应条件温和, 催化剂用量低, 官能团兼容优异，同时所有产物的对映选择性都在 $90 \%$ 以上. 对于链状和环状底物, 反应的最优条件稍有不同, 但都能得到令人满意的结果(图 18). 为了研究该反应的 机理, 作者进行了对照实验. 当选用含有一个双键的三 级溴化物在标准条件下进行反应时, 得到了一对消旋的 非对映异构体(比例为 $1.2: 1$ ). 当使用该三级溴化物在 自由基条件下与三丁基锡氢化物进行反应时，也得到了

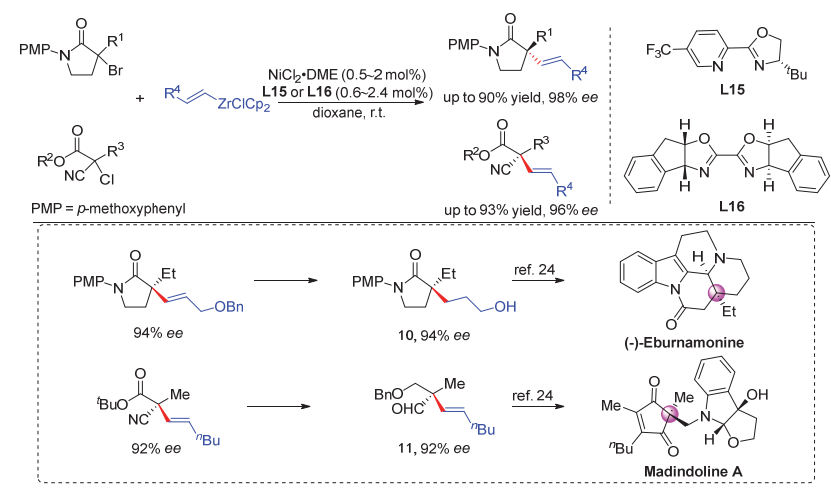

图 18 镍催化叔烷基卤化物与烯基锆试剂的不对称偶联反应

Figure 18 Ni-catalyzed asymmetric coupling of tertiary alkyl halides with alkenyl zirconium reagents
一对消旋的非对映异构体(比例为 $1.4: 1$ ). 2,2,6,6-四甲 基哌啶氧化物(TEMPO)加入到反应能够抑制碳-碳键的 形成. 这些结果证明了该反应过程中可能经过自由基中 间体 8 及 9 . 同时推测镍催化偶联中的对映体汇聚过程 可能是通过从亲电试剂形成自由基中间体来实现的. 最 后，该小组应用此偶联反应，通过简单的原料合成了中 间体 10 和 11 (分别为天然产物(一)-Eburnamonine 和 Madindoline A 的合成前体), 进一步显示了这一反应在 重要分子合成中的应用价值(图 19).

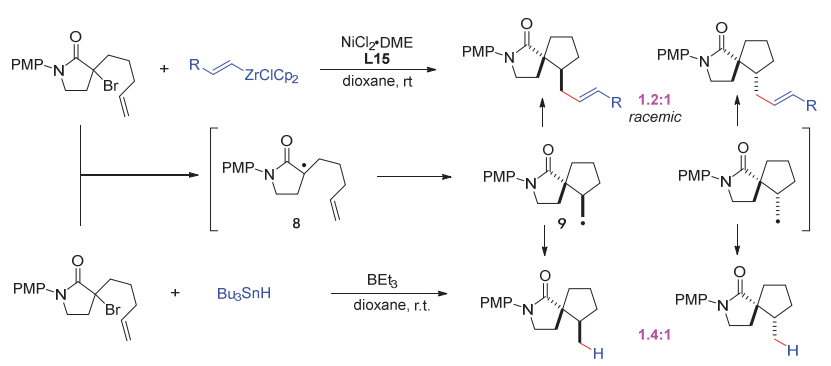

图 19 机理实验

Figure 19 Mechanism studies

\section{4 铜催化的不对称烯基化反应}

\section{1 铜催化的不对称加成反应}

\section{1 .1 碳氧双键的不对称加成反应}

2005 年, Shibasaki 课题组 ${ }^{[25]}$ 开发了铜催化的醛与烯 基硅试剂的不对称加成反应，能够高收率和高对映选择 性地得到一系列手性烯丙醇类化合物. 为了深入了解反 应机理, 该小组进行了一些相关实验, 同时结合动力学 研究结果, 推测在反应过程中通过转金属化步骤得到烯 基铜中间体 12 是速率决策步骤，手性二膦配体的加入 加快了这一过程, 随后该中间体作为活性亲核试剂参与 后面的催化循环(图 20).

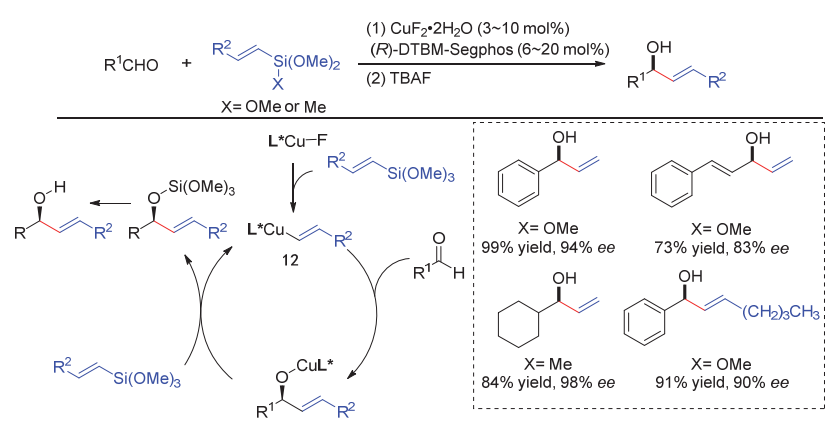

图 20 铜催化醛与烯基硅试剂的不对称加成反应

Figure $20 \mathrm{Cu}$-catalyzed asymmetric addition of aldehydes with alkenyl silicon reagents

2006 年，该小组实现了铜催化的醛与烯基硼试剂 的不对称加成反应 ${ }^{[26]}$. 在还原条件下可以由 $\mathrm{Cu}^{\mathrm{II}} \mathrm{F}_{2}$ 和 5,5'-双 [二(3,5-二叔丁基-4-甲氧基苯基)膦]-4,4'-二-1,3苯并二噁茂(DTBM-Segphos)原位制备得到活性催化剂 $\mathrm{Cu}^{\mathrm{I}} \mathrm{F}-\mathrm{DTBM}-\mathrm{Segphos}$ 复合物. 添加剂的选择能够明显加 
快反应速率，四正丁基铵二氟代三苯基硅酸盐(TBAT) 或 $\mathrm{TBAT}-\mathrm{BF}_{3} \cdot \mathrm{Et}_{2} \mathrm{O}$ 组合能够分别促进与芳香或脂肪醛 的不对称烯基化反应. 具体的催化循环机理如下: 当以 芳香醛为原料, 首先活性催化剂 $\mathrm{Cu}^{\mathrm{I} F}$-DTBM-Segphos 与烯基硼作用，通过转金属化得到活性亲核试剂烯基铜 14, 随后对醛底物进行不对称加成, 得到醇铜中间体 15, 同时诱导出手性. 基于相关文献和实验结果该小组 推测在整个催化循环中, 从 15 到 13 的催化剂周转过程 应该是决速步骤. 在没有添加剂 TBAT 的情况下, 15 通 过转金属化得到 16, 再到 13 的过程非常缓慢, 此步骤 效率不高. 当 TBAT 作为添加剂时, 在反应过程中 TBAT 与烯基硼酸酯底物反应得到氟硼酸盐 $\mathbf{1 7}$, 随后 16 和 17 之间通过简单的阳离子交换, 得到目标产物和再 生催化剂, 显著地促进了决定整个反应速率的催化剂周 转步骤. 当以脂肪醛为原料, 在 $\mathrm{TBAT}-\mathrm{BF}_{3} \cdot \mathrm{Et}_{2} \mathrm{O}$ 组合存 在的条件下, 平衡中应该存在微量的 $\mathrm{BF}_{3}{ }^{[27]}$, 高度亲电 的 $\mathrm{BF}_{3}$ 可以在 15 使醛脱质子生成嗍酸盐 19 前很快捕获 铜醇中间体 15 . 随后 19 和 17 之间进行阳离子交换, 得

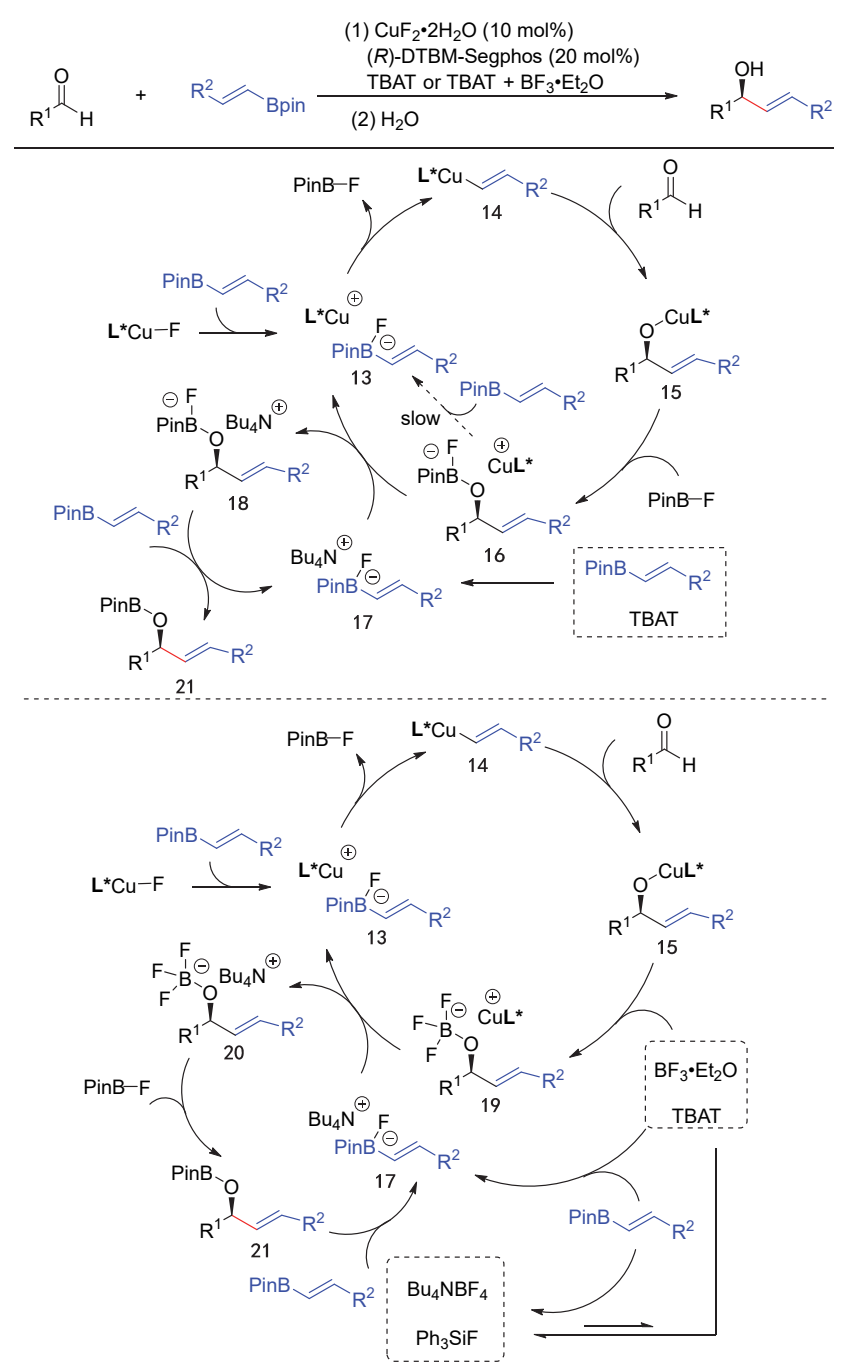

图 21 铜催化醛与烯基嗍试剂的不对加成反应及机理

Figure 21 Cu-catalyzed asymmetric addition of aldehydes with alkenyl boron reagents and mechanism
到 20 和 13. 20 和 $\mathrm{PinB}-\mathrm{F}$ 作用得到 $\mathrm{Bu}_{4} \mathrm{NBF}_{4}$, 再与 $\mathrm{Ph}_{3} \mathrm{SiF}$ 反应得到 $\mathrm{BF}_{3}$, 从而完成催化循环(图 21).

三氟甲基化合物是常见的有机氟化合物，由于三氟 甲基 $\left(\mathrm{CF}_{3}\right)$ 能够显著改变有机化合物的酸性、亲脂性、极 性以及化学和代谢稳定性, 继而可以改变化合物的活 性、毒性和稳定性等性质, 因此在医药、农药和特殊材 料中有广泛应用 ${ }^{[28]} .2006$ 年, Shibasaki 课题组 ${ }^{[29]}$ 使用 $\mathrm{Cu}^{\mathrm{I}} \mathrm{F}-\mathrm{DTBM}-\mathrm{Segphos}$ 复合物催化了三氟甲基酮类化合 物与烯基硅试剂的不对称加成反应，高收率和高对映选 择性地获得手性三氟甲基取代的叔醇类衍生物，最高获 得 84\%的对映选择性(图 22).

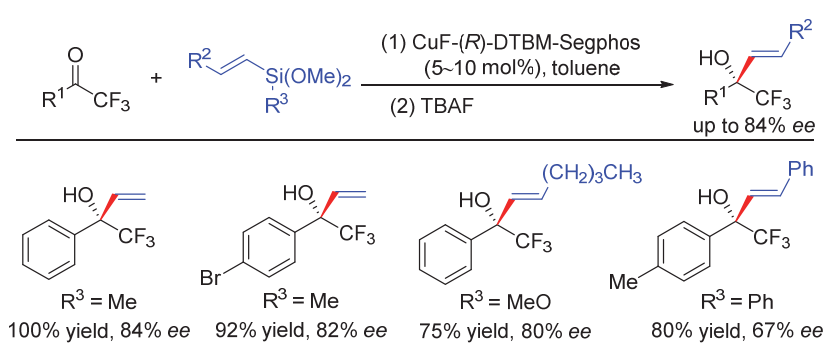

图 22 铜催化三氟甲基酮与烯基硅试剂的不对称加成反应

Figure $22 \mathrm{Cu}$-catalyzed asymmetric addition of trifluoromethyl ketones with alkenyl silicon reagents

2009 年, 该小组 ${ }^{[30]}$ 又实现了氧化吲哚衍生物与烯 基硅试剂的不对称烯基化反应，高收率地得到了一类含 季碳手性中心的烯丙醇衍生物，最高获得 90\%的对映选 择性(图 23).
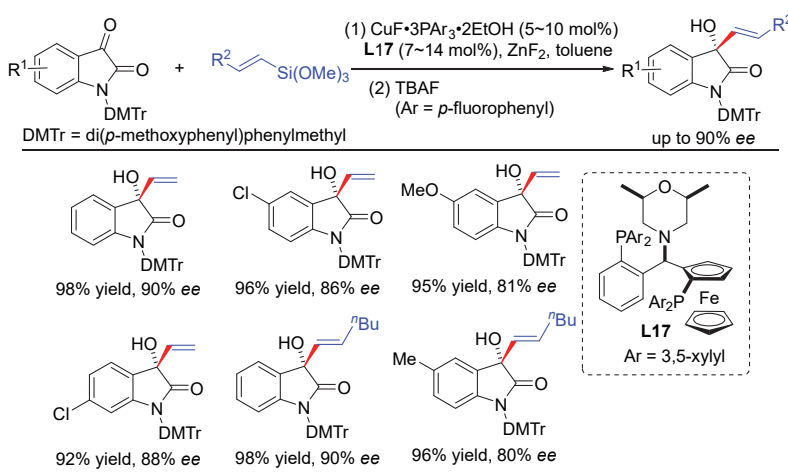

图 23 铜催化氧化吲哚与烯基硅试剂的不对称加成反应

Figure 23 Cu-catalyzed asymmetric addition of oxindoles with alkenyl silicon reagents

\subsection{2 碳碳双键的不对称加成反应}

2010 年, Alexakis 课题组 ${ }^{[31]}$ 报道了铜/手性膦胺催化 的烯基铝试剂(可由商业易得的烯基溴试剂等简单合成) 对环状烯酮化合物的不对称加成反应，最高能以 $96 \%$ 的 对映选择性获得含季碳手性中心的 $\beta$-烯基环烷酮类衍 生物，是天然化合物等的重要前体结构. 随后该小组又 实现了由未保护的末端炔烃的氢铝化生成的烯基铝试 剂, 直接用于铜催化的 $\beta$-取代环烯酮的不对称共轭加成 反应，以良好的收率和对映选择性构建了一个季碳手性 中心. 并且系统研究了由炔烃等为起始原料来高效合成 
烯基铝试剂的方法 ${ }^{[32]}$ (图 24).

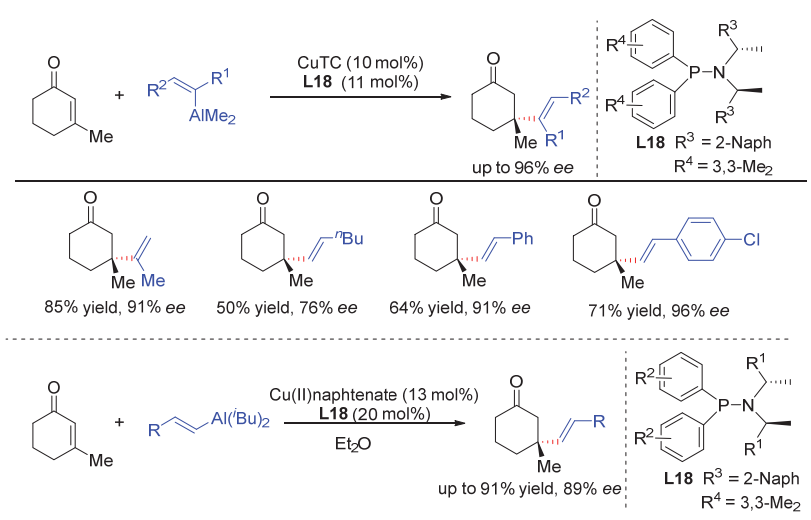

图 24 铜催化环状烯酮与烯基铝试剂的不对称加成反应

Figure 24 Cu-catalyzed asymmetric addition of cyclic enone with alkenyl aluminum reagents

2012 年, Alexakis 课题组 ${ }^{[33]}$ 报道了 $N$-取代的-2-3-脱 氢-4-哌啶酮的不对称烯基化反应，利用该小组开发的 手性膦胺 L18 为手性配体与廉价的环烷酸铜(II)结合的 催化体系, 高收率和高对映选择性地获得不对称加成产 物. 次年, 该小组利用相似的催化体系, 实现了 $\alpha, \beta$-不 饱和内酰胺与烯基铝试剂的不对称 1,4-加成反应, 构建 了一个季碳手性中心并实现了中等至良好的收率和良 好至优异的对映选择性 ${ }^{[34]}$ (图 25).

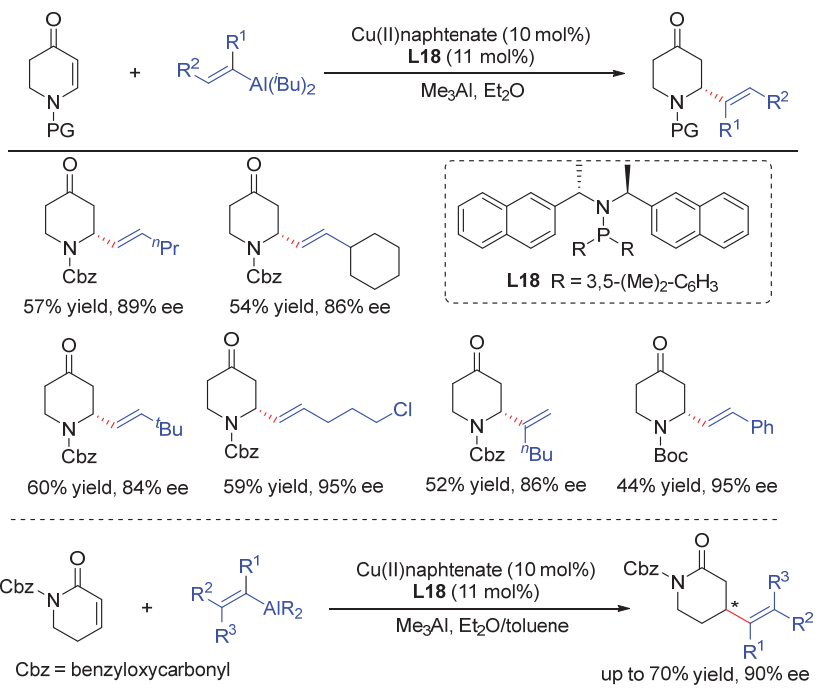

图 25 铜催化 $\alpha, \beta$-不饱和环酮与烯基铝试剂的不对称加成反应

Figure $25 \mathrm{Cu}$-catalyzed asymmetric addition of $\alpha, \beta$-unsaturated cyclic ketones with alkenyl aluminum reagents

2011 年, Hoveyda 课题组 ${ }^{[35]}$ 开发了 $\beta$-取代的环戊烯 酮及环己酮与含硅乙烯基铝试剂的不对称共轭加成反 应. 由空气稳定的 $\mathrm{CuCl}_{2} \cdot 2 \mathrm{H}_{2} \mathrm{O}$ 现场制备的双齿 $N$-杂环 卡宾铜络合物 (NHC-Cu) 为活性催化剂, 通过二异丁基 氢化铝(DIBAL-H)对炔烃进行位点选择性的加氢铝化反 应得到的乙烯基铝试剂为烯基化试剂，以 48\% 95\%的 收率获得 78\% 97\% 的对映选择性得到含季碳手性中心
的目标产物. 产物中的乙烯基硅烷部分可以被官能化, 高收率地获得酰基、乙烯基碘或脱甲硅烷基的烯烃化合 物，同时 $e e$ 值没有损失. 最后该小组利用此方法实现了 Riccardiphenol B 的高效不对称合成(图 26).

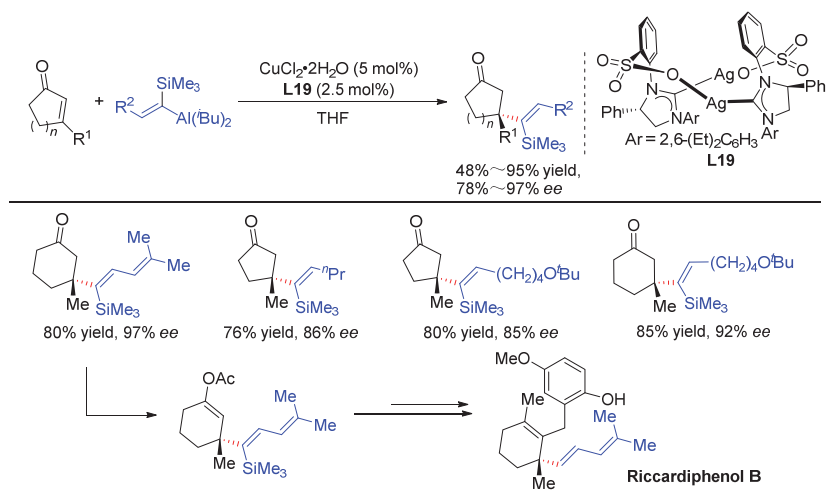

图 26 铜催化环烯酮与含硅烯基铝试剂的不对称加成反应

Figure $26 \mathrm{Cu}$-catalyzed asymmetric addition of cyclic enone with Si-containing alkenyl aluminum reagents

2017 年, Marek 课题组 ${ }^{[36]}$ 利用噻吩-2-甲酸亚铜 (CuTc)为催化剂, 由炔烃化合物原位生成的烯基铝试剂 为烯基化试剂, 实现了其与环丙烯类化合物的不对称加 成反应. 以中等到优秀的对映选择性获得一系列重要的 手性烯基环丙烷类衍生物(图 27).

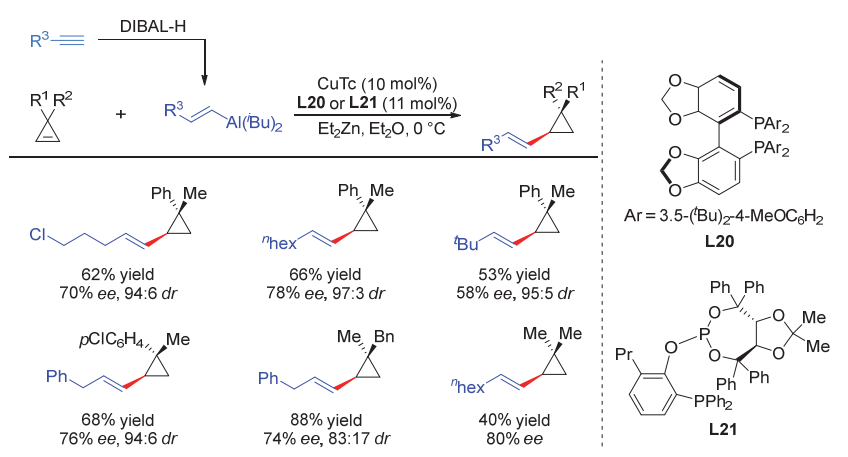

图 27 铜催化环丙烯与烯基铝试剂的不对称加成反应

Figure 27 Cu-catalyzed asymmetric addition of cyclopropenes with alkenyl aluminum reagents

同年，孟繁柯课题组 ${ }^{[37]}$ 报道了 $\mathrm{NHC}-\mathrm{Cu}$ 催化的烯基 硼酸酯对缺电子双键的不对称烯基化反应，各种官能化 的烯基底物参与反应都能得到相应的目标产物，最高获 得 $98 \%$ 的收率和 $99 \%$ 的对映选择性, 并利用密度泛函理 论计算阐述了手性控制的起源. 推测的机理如下: 首先 $\mathrm{Cu}^{\mathrm{I}}$ 配合物促进链烯基- $\mathrm{B}(\mathrm{pin})$ 发生转金属化生成烯基$\mathrm{Cu}$ 复合物 22, 随后与二乙基亚芐基丙二酸酯底物配位 形成 $\pi$ 配合物 23. 烯基迁移到 $\pi$ 键得到 $\mathrm{Cu}^{\mathrm{I}}$ 配合物 24, 迅速异构为 $\mathrm{Cu}$-烯醇中间体 25. 随后与 $\mathrm{NaO}^{t} \mathrm{Bu}$ 作用得 到 26, 再异构得到加成产物, 同时再生催化剂, 进入下 一个循环(图 28).

2020 年, Hoveyda 课题组 ${ }^{[38]}$ 报道了 $\mathrm{NHC}-\mathrm{Cu}$ 催化的 一系列 $E-、 Z-$ 、二取代以及三取代的烯基铝试剂(由相 
应的炔烃现场合成)对不饱和碳碳双键的不对称加成反 应，官能团耐受性优异，能够以高达 $89 \%$ 的收率和 $98 \%$ 的对映选择性获得烯基化产物. 此类双取代以及 $E-$, 或 $Z$-三取代的产物中, 烯基部分能够以多种方式进行官能 化, 从而方便合成一系列天然产物和药物活性分子(图 29).

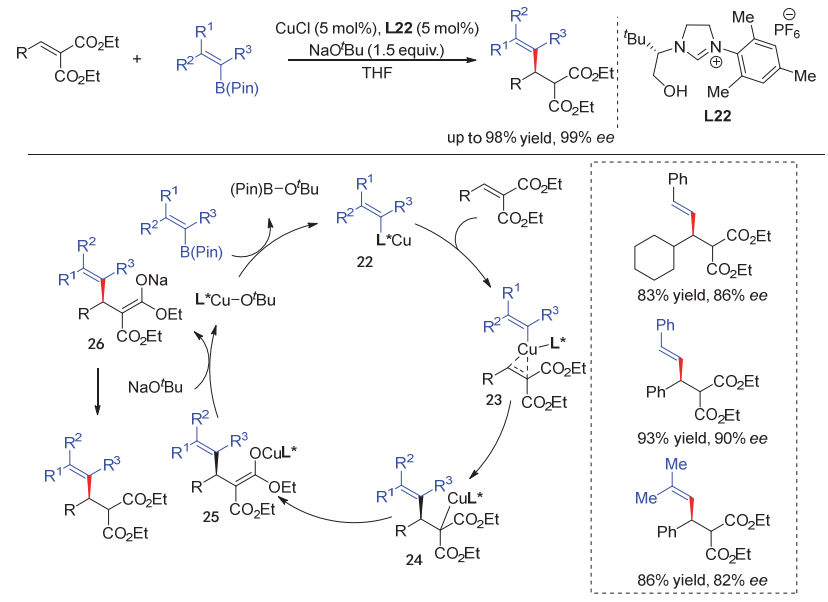

图 28 铜催化 $\alpha, \beta$-不饱和化合物与烯基硼试剂的不对称加成反应及 机理

Figure 28 Cu-catalyzed asymmetric addition of $\alpha, \beta$-unsaturated compounds with alkenyl boron reagents and mechanism

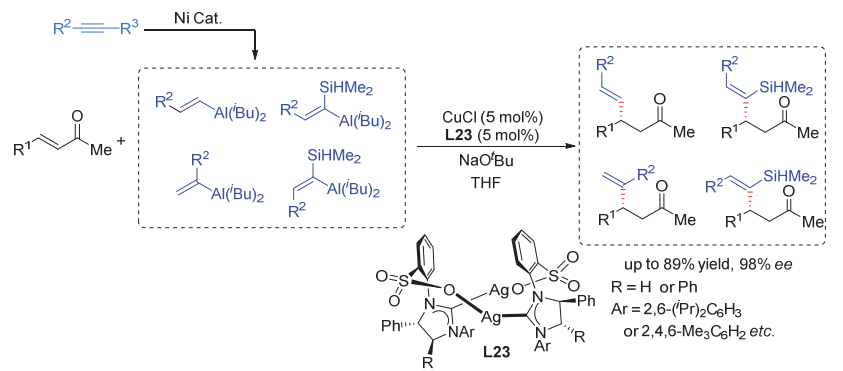

图 29 铜催化 $\alpha, \beta$-不饱和化合物与烯基铝试剂的不对称加成反应

Figure 29 Cu-catalyzed asymmetric addition of $\alpha, \beta$-unsaturated compounds with alkenyl aluminum reagents

\section{2 铜催化的不对称偶联反应}

过渡金属催化的烯丙基取代反应作为一类重要的 形成 $\mathrm{C}-\mathrm{C}$ 键和 $\mathrm{C}-\mathrm{X}$ 键 (如 $\mathrm{C}-\mathrm{O} 、 \mathrm{C}-\mathrm{N}$ 和 $\mathrm{C}-\mathrm{S}$ 键等) 的反应, 现已被广泛应用于天然产物和具有重要生物活 性药物的合成中 ${ }^{[39]}$. 在这类反应中通常需要经过 $\pi$-烯丙 基金属配合物中间体的过程. 不同的是，当软亲核试剂 (例如, 烯醇酸酯、丙二酸酯)参与反应时, 通常会直接进 攻 $\pi$-烯丙基金属配合物的碳原子; 当硬亲核试剂(例如, 有机铝试剂、有机嗍试剂)参与反应时, 一般先通过转金 属化过程与 $\pi$-烯丙基金属作用得到金属配合物中间体, 随后通过还原消除来构建新的碳-碳键, 从而得到目标 产物(图 30).

烯丙醇衍生物是一类常用的烯丙基底物，广泛应用 于有机金属试剂参与的铜催化交叉偶联反应中. 2008 年, Hoveyda 课题组 ${ }^{[40]}$ 利用铜为金属催化剂, 卡宾为手
性配体，催化了链状磷酸烯丙酯类化合物与烯基铝试剂 的不对称交叉偶联反应，最高获得大于 $98 \%$ 的对映选择 性，同时该小组实现了这一反应的克级放大(图 31).

Soft Nuclephiles

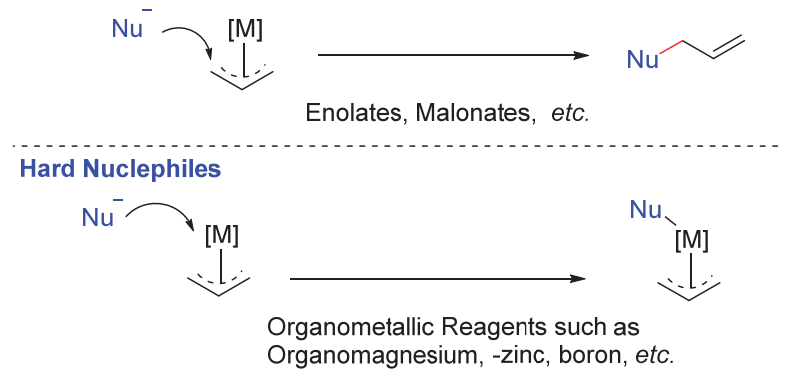

图 30 软与硬亲核试剂比较

Figure 30 Soft vs hard nucleophiles

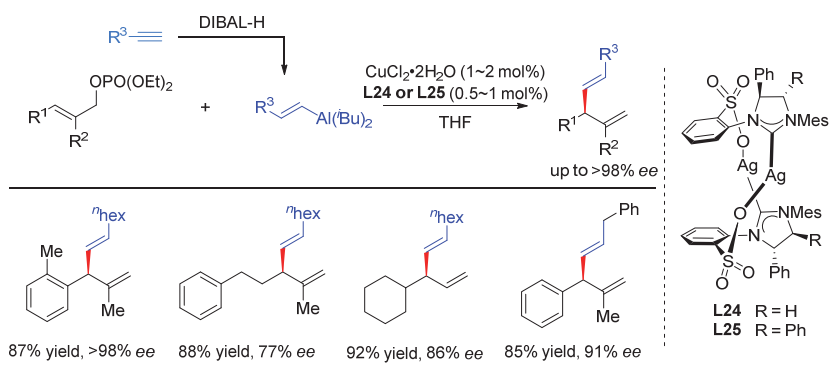

图 31 铜催化磷酸烯丙酯与烯基铝试剂的不对称偶联反应

Figure $31 \mathrm{Cu}$-catalyzed asymmetric coupling of allylic phosphates with alkenyl aluminum reagents

2010 年该小组利用类似的催化体系，高对映选择 性地实现了端位二取代烯丙酯与烷基或芳基取代的乙 烯基铝试剂的交叉偶联反应，得到含季碳立体中心的 1,4-二烯类化合物. 由于炔烃与二异丁基氢化铝直接加 成制备芳基和乙烯基取代的金属铝试剂的反应低效，该 小组最近通过镍催化剂的添加实现了相应末端炔烃的 选择性还原，从而高效制备相应烯基铝试剂. 最后通过 该方法实现了天然产物 Bakuchiol 的简洁高效合成 ${ }^{[41]}$ (图 32).

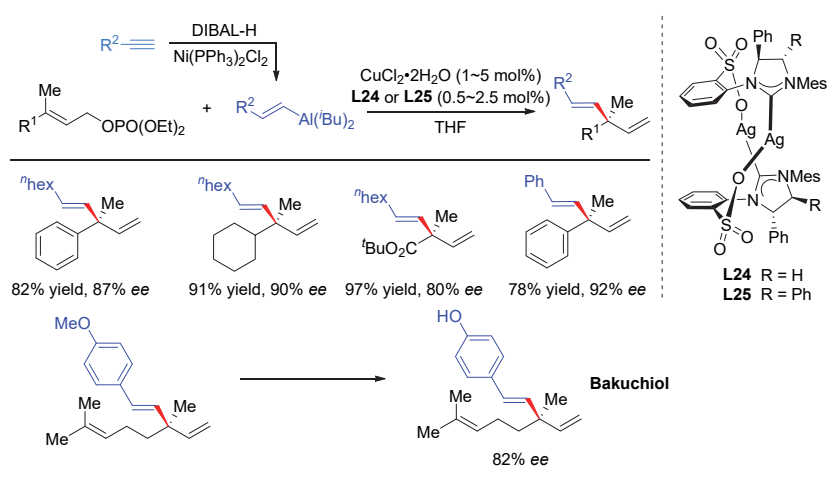

图 32 铜催化三取代磷酸烯丙酯与烯基铝试剂的不对称偶联反应 Figure $32 \mathrm{Cu}$-catalyzed asymmetric coupling of trisubstituted allylic phosphates with alkenyl aluminum reagents 
同年 Hoveyda 课题组通过反应条件的进一步篮选, 实现了磷酸烯丙酯与含硅烯基铝试剂的交叉偶联反应, $E$ 式和 $Z$ 式烯基铝试剂都能得到相应的产物, 最高获得 大于 $98 \%$ 的对映选择性. 最后该小组利用此反应, 能够 以 $42 \%$ 的总收率实现(一)-Nyasol 的高效不对称合成 ${ }^{[42]}$ (图 33).

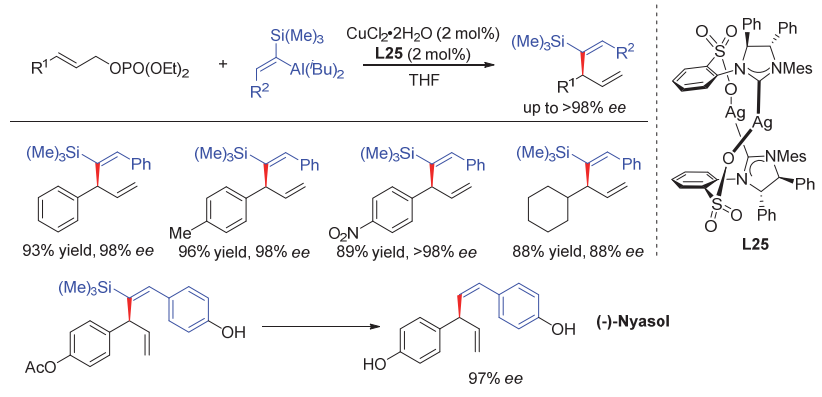

图 33 铜催化磷酸烯丙酯与含硅烯基铝试剂的不对称偶联反应

Figure $33 \mathrm{Cu}$-catalyzed asymmetric coupling of allylic phosphates with Si-containing alkenyl aluminum reagents

2012 年, Hoveyda 课题组 ${ }^{[43]}$ 报道了铜催化的端位二 取代磷酸烯丙酯与烯基喼试剂的不对称偶联反应, 高对 映选择性地构建了一个季碳手性中心. 值得注意的是当 以含缩醛结构的烯基硼试剂作为亲核试剂时, 在标准条 件下反应 $24 \mathrm{~h}$ 后, 用含硅胶的乙醚溶液处理, 能够以最 高 $90 \%$ 的收率和 $96 \%$ 的对映选择性得到含两个不饱和 双键的醛产物。吗啡生物合成中的重要中间体 Pummerer 酮可以由该方法高效合成(图 34).

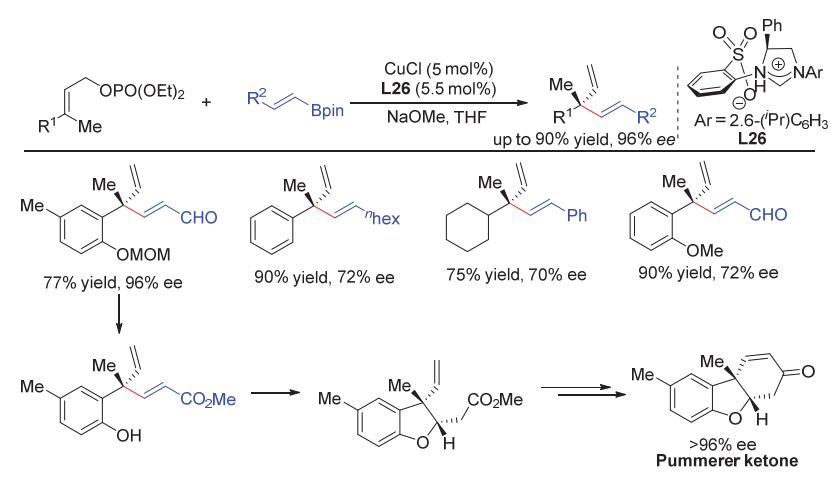

图 34 铜催化三取代磷酸烯丙酯与烯基嗍试剂的不对称偶联反应

Figure 34 Cu-catalyzed asymmetric coupling of trisubstituted allylic phosphates with alkenyl boron reagents

2014 年, 该小组 ${ }^{[44]}$ 利用相似的催化体系实现了不 同取代基的磷酸烯丙酯与不同类型的烯基嗍试剂的不 对称反应, 得到一系列 1,4-二烯类衍生物. 乙烯基-、E或 Z-二取代的烯基-、1,1-二取代的烯基-、无环或杂环 三取代的烯基都能以高达 98\%的收率，大于 $98: 2$ 的 $\mathrm{S}_{\mathrm{N}} 2^{\prime}: \mathrm{S}_{\mathrm{N}} 2$ 的区域选择性以及大于 $98 \%$ 的对映选择性得 到相应的手性烯基化产物(图 35).

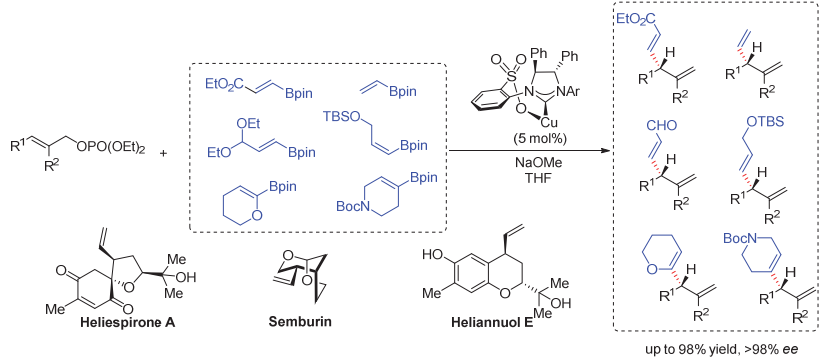

图 35 铜催化磷酸烯丙酯与烯基硼试剂的不对称偶联反应

Figure 35 Cu-catalyzed asymmetric coupling of allylic phosphates with alkenyl boron reagents

\section{5 其他丰产金属催化的不对称烯基化反应}

\section{1 锌催化的不对称烯基化反应}

2015 年, Trost 课题组 ${ }^{[45]}$ 设计了一类非 C2 对称的 ProPhenol 配体，应用到锌催化的醛亚胺与烯基锆试剂 的不对称加成反应中，以优异的收率和对映选择性得到 一系列手性烯丙胺类化合物. 新一代非 C2 对称的 ProPhenol 配体能够通过电子区分双核 Zn-ProPhenol 催 化剂中的手性空间来提高选择性. 推测该反应的机理 为: 从双核 Zn-ProPhenol 配合物 27 出发, 首先与烯基锆 试剂发生转金属化, 烯基连接到具有手性环境的锌催化 剂上，得到中间体 28. 亚胺上的 $N$-叔丁氧羰基 $(N-\mathrm{Boc})$ 与两个锌原子进行双齿配位以及通过在 ProPhenol 配体 的一侧引入吸电子基团来实现电子分化. 随后乙烯基锌 物种与配位亚胺通过六元过渡态 29 发生亲核加成, 得 到对映体富集的烯丙胺 30 , 最后与乙烯基锆物种进行 转金属化, 释放出产物 $\mathbf{3 1}$, 在后处理过程中质子化后得 到所需的手性烯丙胺产物(图 36).

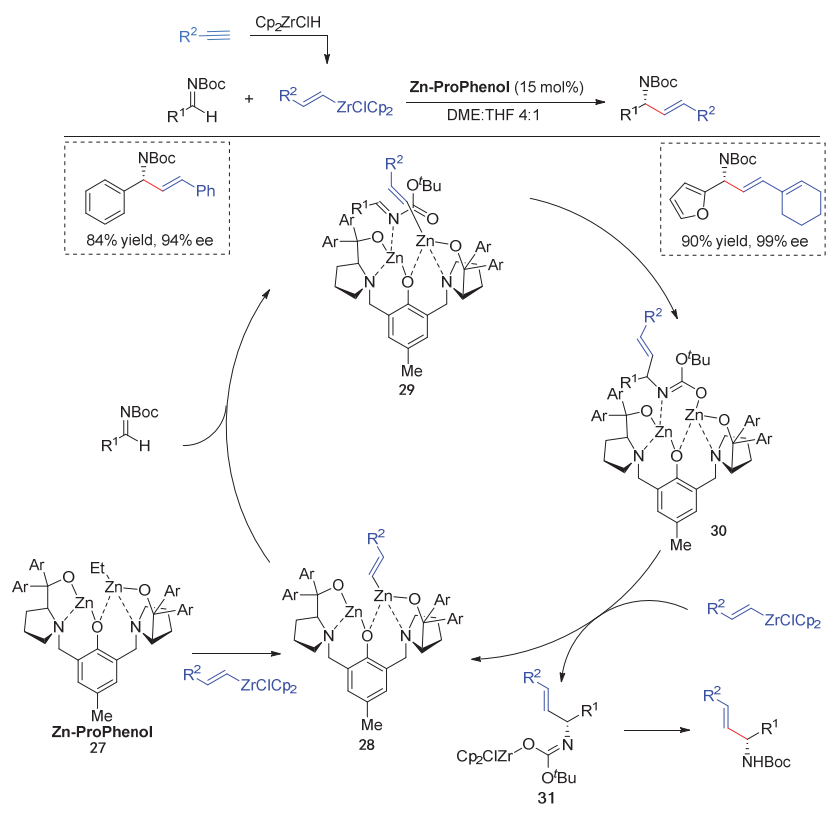

图 36 锌催化醛亚胺与烯基锆试剂的不对称加成反应及机理

Figure 36 Zn-catalyzed asymmetric addition of aldimines with alkenyl zirconium reagents and mechanism 


\section{2 铁催化的不对称烯基化反应}

2015 年, Nakamura 课题组 ${ }^{[46]}$ 报道了一例铁催化的 有机卤化物与芳基/烯基镁试剂的不对称交叉偶联反应， 以中等到优秀的收率和对映选择性得到目标产物. 唯一 一例以烯基镁试剂为底物的反应，能够以 $52 \%$ 的收率以 及 $82 \%$ 的对映选择性得到手性烯基化产物. 机理实验表 明反应过程中存在自由基, 因此该小组提出了两个可能 的催化循环机理: 由二价铁 32 启动, 它是由部分还原产 生的三乙酰丙酮铁 $\left(\mathrm{Fe}(\mathrm{acac})_{3}\right)$, 在少量有机镁试剂和过 量的 $\alpha$-卤代酯的条件下生成. 该物种 32 算取底物中的 卤素生成烷基自由基中间体 34 和铁物种 33. 首先在笼 内循环机理中 ${ }^{[47]}$, 烷基自由基 34 与 33 作用在溶剂笼中 得到偶联产物和铁配合物 35,35 与有机镁试剂发生转金 属化再生 32. 然而, 根据相关的实验结果, 该小组更倾 向于笼外循环机理 ${ }^{[48]}$, 其中烷基自由基中间体 33 从溶 剂笼逃逸出来与另一种二价铁(II)物种 32 反应形成偶联 产物, 同时得到一价铁(I)物种 36. 随后配合物 33 和 36 作用得到 35 和 32, 35 又与有机镁试剂转金属化得到 32, 进入下一个循环(图 37).

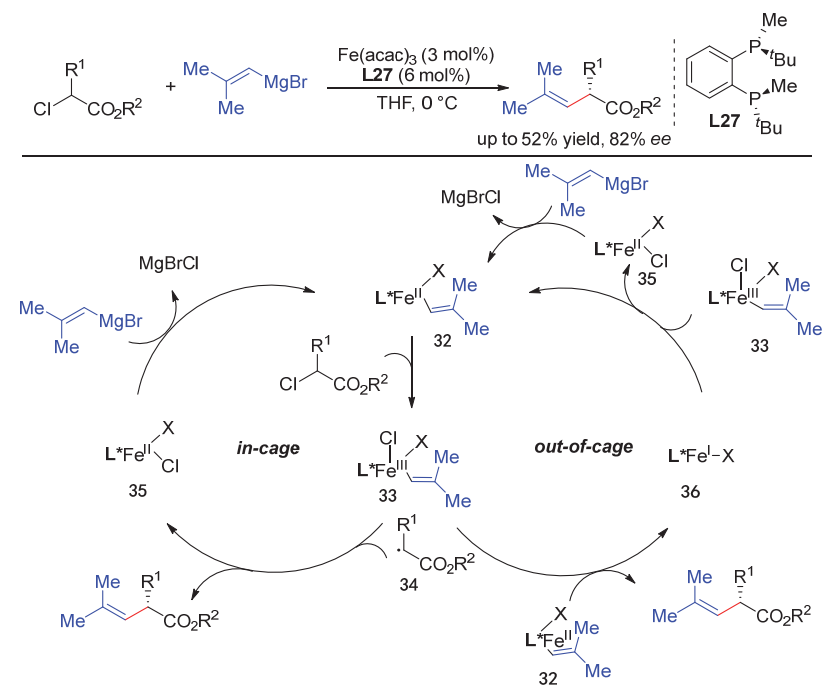

图 37 铁催化 $\alpha$-氯代酯与烯基镁试剂的不对称偶联反应及机理

Figure 37 Fe-catalyzed asymmetric coupling of $\alpha$-chloroesters with alkenyl magnesium reagents and mechanism

\section{3 钪催化的不对称烯基化反应}

2006 年, Evans 课题组 ${ }^{[49]}$ 实现了钪催化的 $N$-苯基乙 醛酰胺与烯基硅试剂的不对称加成反应，一种合成对映 体纯 $\beta, \gamma$-不饱和 $\alpha$-差基酸衍生物的高效方法. 反应条件 温和, 以空气和水分稳定的三甲基乙烯基硅烷作为烯基 化试剂, 考虑到醛底物不太稳定容易发生水解或者酯交 换, 因此反应中需要加入一定量的分子䇻以稳定醛底 物. 值得一提的是, 所有产物基本均为高度结晶的固体, 非常适合工业化过程(图 38).

\section{6 总结与展望}

如上所述，钴镍铜等丰产金属催化的烯基金属试剂

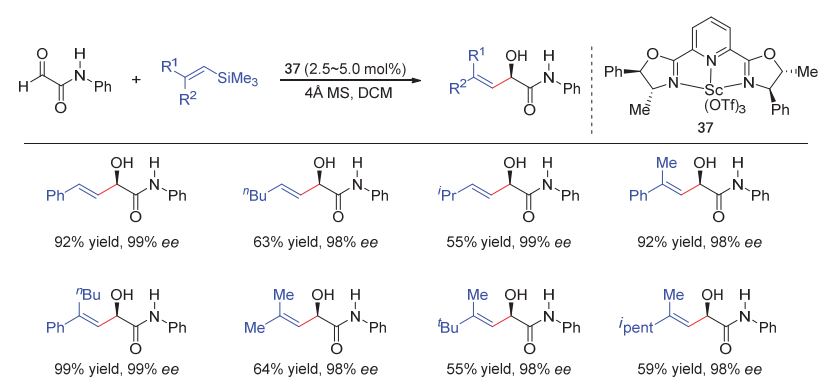

图 38 钪催化醛与烯基硅试剂的不对称加成反应

Figure 38 Sc-catalyzed asymmetric addition of aldehydes with alkenyl silicon reagents

作为亲核试剂的不对称烯基化反应已经成为构建烯丙 位手性中心的重要方法之一. 虽然近年来在这一领域取 得了一定的进展，但还有许多需要攻克的难题。如在钴 催化的此类不对称加成反应中，烯基金属试剂仅限于空 气和水稳定的烯基硼试剂，所以拓展更为广泛的烯基金 属试剂范围以及季碳手性中心的构筑仍然是极具挑战 性的工作．总体而言，铁锌钪等丰产金属催化的此类反 应研究较少，同时在这一领域中利用不对称偶联的方法 来构建含烯基的手性产物也鲜有报道，仅有 $\mathrm{Fu}$ 和张万 斌课题组开发的几个例子. 考虑到铁钴镍铜等丰产金属 独特的催化活性和反应选择性以及近年来所取得的成 果，未来将会有更多烯基金属试剂作为亲核试剂、丰产 金属催化的不对称烯基化反应被开发出来，丰富有机化 学的理论内容, 开发更多的潜在应用.

\section{作者简介}

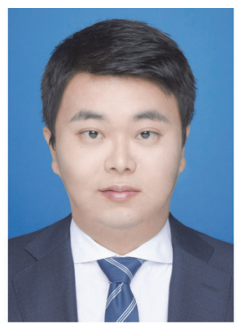

吴良, 2020 年在上海交通大学获得博士学位(导师：张万 斌教授). 目前在上海交通大学张万斌教授棵题组从事博士后 研究工作，主要研究方向为丰产金属催化的不对称反应.

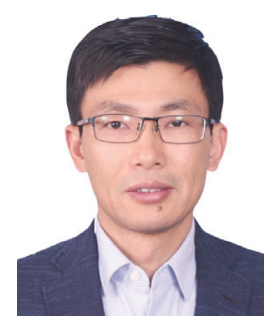

申杰峰, 博士, 上海交通大学药学院副研究员, 硕士研究 生导师. 2012 博士毕业于上海交通大学化学化工学院(导师: 张万斌教授); 同年进入上海交通大学药学院从事博士后研究 工作(导师：刘燕刚教授). 2014 年至今就职于上海交通大学药 学院, 主要研究方向为不对称催化、化学工艺及新药开发研 究. 


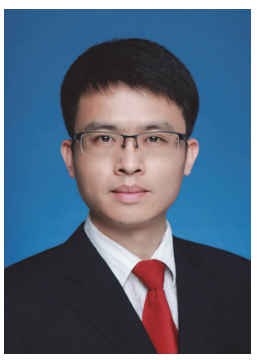

陈建中, 上海交通大学化学化工学院副研究员. 本科毕 业于浙江工业大学; 硕士毕业于华东理工大学(导师: 赵敏副 教授); 博士毕业于上海交通大学(导师: 张万斌教授), 同年本 校从事博士后研究(导师: 颜德岳院士). 自 2015 年起在上海交 通大学主要从事不对称反应研究, 新型配体的设计、合成及应 用, 药物和香料等合成工艺研究等.

\section{References}

[1] (a) Catalysis without Precious Metals, Ed.: Bullock, R. M., Wiley-VCH, Weinheim, 2010. (b) Morris, R. H. Chem. Soc. Rev. 2009, 38, 2282. (c) Zhang, L.; Huang, Z. Synlett 2013, 1745. (d) Zhu, S.-F.; Zhou, Q.-L. Natl. Sci. Rev. 2014, 1, 580. (e) Guo, N.; Zhu, S. Chin. J. Org. Chem. 2015, 35, 1383 (in Chinese). (郭娜, 朱 守非, 有机化学, 2015, 35, 1383.) (f) Li, J.; Liu, K.; Duan, X.; Liu, J. Chin. J. Org. Chem. 2017, 37, 314 (in Chinese). (李娟华, 刘昆 明，段新方，刘晋彪，有机化学， 2017, 37, 314.) (g) Wu, Z.; Zhang, W. Chin. J. Org. Chem. 2017, 37, 2250 (in Chinese). (吴正兴, 张方 斌, 有机化学, 2017, 37, 2250.) (h) Obligacion, J. V.; Chirik, P. J. Nat. Rev. Chem. 2018, 2, 15. (i) Chen, J.; Lu, Z. Org. Chem. Front. 2018, 5, 260. (j) Chen, J.; Guo, J.; Lu, Z. Chin. J. Chem. 2018, 36, 1075. (k) Fu, X.; Zhao, W. Chin. J. Org. Chem. 2019, 39, 625 (in Chinese). (付晓飞, 赵文献, 有机化学, 2019, 39, 625.) (1) Sun, Y.; Guan, R.; Liu, Z.; Wang, Y. Chin. J. Org. Chem. 2020, 40, 899 (in Chinese). (孙越, 关瑞, 刘兆洪, 王也铭, 有机化学, 2020,40, 899.) (m) Guo, J.; Cheng, Z.; Chen, J.; Chen, X.; Lu, Z. Acc. Chem. Res. 2021, 54, 2701. (n) Chen, J.; Xi, T.; Lu, Z. Org. Lett. 2014, 16, 6452. (o) An, L.; Tong, F.; Zhang, X. Acta Chim. Sinica 2018, 76, 977 (in Chinese). (安伦, 童非非, 张新刚, 化学学报, 2018, 76, 977.) (p) Cheng, B.; Liu, W.; Lu, Z. J. Am. Chem. Soc. 2018, 140, 5014. (q) Wang, S.; Sun, M.; Zhang, H.; Zhang, J.; He, Y.; Feng, Z. CCS Chem. 2020, 2, 2164. (r) Zou, S.; Zhang, T.; Wang, S.; Huang, H. Chin. J. Chem. 2020, 38, 389. (s) Wang, G.-X.; Yin, J.; Li, J.; Yin, Z.-B.; Wu, B.; Wei, J.; Zhang, W.-X.; Xi, Z. CCS Chem. 2021, 3, 308. (t) Xu, S.; Liu, G.; Huang, Z. Chin. J. Chem. 2021, 39, 585. (u) Li, W.-D.; Chen, J.; Zhu, D.-Y.; Xia, J.-B. Chin. J. Chem. 2021, 39, 614 .

[2] (a) Pellissier, H.; Clavier, H. Chem. Rev. 2014, 114, 2775. (b) Gandeepan, P.; Cheng, C.-H. Acc. Chem. Res. 2015, 48, 1194. (c) Gu, Z.; Ji, S. Acta Chim. Sinica 2018, 76, 347 (in Chinese). (顾正洋, 纪顺 俊, 化学学报, 2018, 76, 347.) (d) Sun, Y.; Ding, Q.; Yu, Y.; He, Y.; Huang, F. Chin. J. Org. Chem. 2019, 39, 3363 (in Chinese). (孙义 明, 丁奇峰, 于杨, 何益得, 黄菲, 有机化学, 2019, 39, 3363.) (e) Dai, Z.; Yu, Z.; Bai, Y.; Li, J.; Peng, J. Chin. J. Org. Chem. 2020, 40, 1177 (in Chinese). (代自男, 余泽浩, 白赢, 厉嘉云, 彭家建, 有 机化学, 2020, 40, 1177.) (f) Wen, J.; Wang, F.; Zhang, X. Chem. Soc. Rev. 2021, 50, 3211. (g) Gao, K.; Lee, P.-S.; Fujita, T.; Yoshikai, N. J. Am. Chem. Soc. 2010, 132, 12249. (h) Friedfeld, M. R.; Shevlin, M.; Hoyt, J. M.; Krska, S. W.; Tudge, M. T.; Chirik, P. J. Science 2013, 342, 1076. (i) Chen, Q. A.; Kim, D. K.; Dong, V. M. J. Am. Chem. Soc. 2014, 136, 3772. (j) Yang, J.; Yoshikai, N. J. Am. Chem. Soc. 2014, 136, 16748. (k) Zhang, L.; Zuo, Z.; Wan, X.; Huang, Z. J. Am. Chem. Soc. 2014, 136, 15501. (1) Santhoshkumar, R.; Mannathan, S.; Cheng, C.-H. J. Am. Chem. Soc. 2015, 137, 16116. (m) Friedfeld, M. R.; Shevlin, M.; Marguloeux, G. W.; Campeau, L.; Chirik, P. J. J. Am. Chem. Soc. 2016, 138, 3314. (n) Wu, L.; Shao, Q.; Yang, G.; Zhang, W. Chem. Eur. J. 2018, 24, 1241. (o) Hu, Y.; Zhang, Z.; Zhang, J.; Liu, Y.; Gridnev, I. D.; Zhang, W. Angew. Chem. Int. Ed. 2019, 58, 15767. (p) Li, X.; Wu, X.; Tang, L.; Xie, F.; Zhang, W. Chem. Asian J. 2019, 14, 3835. (q) Cheng, Z.; Xing, S.; Guo, J.; Cheng, B.; Hu, L.-F.; Zhang, X.-H.; Lu, Z. Chin. J. Chem. 2019, 37, 457. (r) Wu, L.; Shao, Q.; Kong, L.; Chen, J.;
Wei, Q.; Zhang, W. Org. Chem. Front. 2020, 7, 862. (s) Lin, X.; Tan, Z.; Yang, W.; Yang, W.; Liu, X.; Feng, X. CCS Chem. 2020, 2, 1423. (t) Hu, Y.; Zhang, Z.; Liu, Y.; Zhang, W. Angew. Chem. Int. Ed. 2021, 60, 16989.

[3] (a) Tasker, S. Z.; Standley, E. A.; Jamison, T. F. Nature 2014, 509, 299. (b) Butt, N. A.; Zhang, W. Chem. Soc. Rev. 2015, 44, 7929. (c) Choi, J; Fu, G. C. Science 2017, 356, eaaf7230. (d) Fu, G. C. ACS Cent. Sci. 2017, 3, 692. (e) Zhang, Z.; Butt, N. A.; Zhou, M.; Liu, D.; Zhang, W. Chin. J. Chem. 2018, 36, 443. (f) Quan, M.; Wu, L.; Yang, G.; Zhang, W. Chem. Commun. 2018, 54, 10394. (g) Chen, J.; Butt, N. A.; Zhang, W. Res. Chem. Intermed. 2019, 45, 5959. (h) Liu, Y.; Dong, X.-Q.; Zhang, X. Chin. J. Org. Chem. 2020, 40, 1096 (in Chinese). (刘元华, 董秀琴, 张绪穆, 有机化学, 2020,40, 1096.) (i) Cheng, L.; Zhou, Q. Acta Chim. Sinica 2020, 78, 1017 (in Chinese). (程否, 周其林, 化学学报, 2020, 78, 1017.) (j) Dai, H.; Wu, F.; Bai, D. Chin. J. Org. Chem. 2020, 40, 1423 (in Chinese). (代 洪雪, 吴芬, 白大昌, 有机化学, 2020, 40, 1423.) (k) Chen, S.; Zhao, Y. Chin. J. Org. Chem. 2020, 40, 3078 (in Chinese). (陈思, 赵延川, 有机化学, 2020, 40, 3078.) (1) Quan, M.; Tang, L.; Shen, J.; Yang, G.; Zhang, W. Chem. Commun. 2017, 53, 609. (m) Zhang, Y.; He, J.; Song, P.; Wang, Y.; Zhu, S. CCS Chem. 2020, 2, 2259. (n) Li, Z.; Wu, D.; Ding, C.; Yin, G. CCS Chem. 2020, 2, 576. (o) Li, B.; Chen, J.; Zhang, Z.; Gridnev, I. D.; Zhang, W. Angew. Chem. Int. Ed. 2019, 58, 7329. (p) Liu, D.; Li, B.; Chen, J.; Gridnev, I. D.; Yan. D.; Zhang, W. Nat. Commun. 2020, 11, 5935. (q) Hu, Y.; Chen, J.; Li, B.; Zhang, Z.; Gridnev, I. D.; Zhang, W. Angew. Chem. Int. Ed. 2020, 59, 5371. (r) Chen, J.; Zhang, W. Chin. J. Org. Chem. 2020 40, 4372 (in Chinese). (陈建中, 张万斌, 有机化学, 2020, 40, 4372. ) (s) Li, B.; Liu, D.; Hu, Y.; Chen, J.; Zhang, Z.; Zhang, W. Eur. J. Org. Chem. 2021, 3421. (t) Zhu, C.; Yue, H.; Nikolaienko, P.; Rueping, M. CCS Chem. 2020, 2, 179. (u) Han, X.-W.; Zhang, T.; Yao, W.-W.; Chen, H.; Ye, M. CCS Chem. 2020, 2, 955. (v) Xiao, C.; Xiao, W. Chin. J. Org. Chem. 2020, 40, 3004 (in Chinese). (肖联, 肖文精, 有机化学, 2020, 40, 3004.)

[4] (a) Alexakis, A.; Bäckvall, J. E.; Krause, N.; Pámies, O.; Diéguez, M. Chem. Rev. 2008, 108, 2796. (b) Shi, Z.; Zhang, C.; Tang, C.; Jiao, N. Chem. Soc. Rev. 2012, 41, 3381. (c) Guo, X.-X.; Gu, D.-W.; Wu, Z.; Zhang W. Chem. Rev. 2015, 115, 1622 (d) Liu, Y.; Zhang, W. Chin. J. Org. Chem. 2016, 36, 2249 (in Chinese). (刘媛媛, 张方 斌, 有机化学, 2016, 36, 2249.) (e) Duan, X.; Liu, N.; Wang, J.; Ma, J. Chin. J. Org. Chem. 2019, 39, 661 (in Chinese). (段希炎, 刘宁, 王佳, 马军营，有机化学, 2019, 39, 661.) (f) Xie, J.; Wang, X.; Wu, F.; Zhang, J. Chin. J. Org. Chem. 2019, 39, 3026 (in Chinese). (谢建 伟, 汗小创, 吴丰田, 张洁, 有机化学, 2019, 39, 3026.) (g) Lei, L.; Li, C.; Mo, D. Chin. J. Org. Chem. 2019, 39, 2989 (in Chinese) (雷禄, 李承璟, 莫冬亮, 有机化学, 2019, 39, 2989.) (h) Wang, C.; Zhou, F.; Zhou, J. Chin. J. Org. Chem. 2020, 40, 3065 (in Chinese). (王才, 周锋, 周剑, 有机化学, 2020, 40, 3065.) (i) Wang, M.; Zhang, Z.; Xie, F.; Zhang, W. Chem. Commun. 2014, 50, 3163. (j) Wu, X.; Xie, F.; Ling, Z.; Tang, L.; Zhang, W. Adv. Synth. Catal. 2016, 358, 2510. (k) Zhang, D.-D.; Liu, Y.-L.; Wang, Y.; Wei, H.; Shi, M.; Wang, F.-J. Chin. Chem. Lett. 2016, 27, 563. (1) Ling, Z.; Singh, S.; Xie, F.; Wu, L.; Zhang, W. Chem. Commun. 2017, 53, 5364. (m) Shao, Q.; Wu, L.; Chen, J.; Gridnev, I. D.; Yang, G.; Xie, F.; Zhang, W. Adv. Synth. Catal. 2018, 360, 4625. (n) Ling, Z.; Xie, F.; Gridnev, I. D., Terada, M.; Zhang, W. Chem. Commun. 2018, 54, 9446. (o) Wu, X.; Xie, F.; Gridnev, I. D.; Zhang, W. Org. Lett. 2018 20, 1638. (p) Cheng, Z.; Chen, P.; Liu, G. Acta Chim. Sinica 2019, 77, 856 (in Chinese). (成忠明, 陈品红, 刘国生, 化学学报, 2019, 77, 856.) (q) You, Y.; Van Pham, Q.; Ge, S. CCS Chem. 2019, 1, 455. (r) Lin, F.; Liang, Y.; Li, X.; Song, S.; Jiao, N. Acta Chim. Sinica 2019, 77, 906 (in Chinese). (林凤闺蓉, 梁宇杰, 畉釒耀, 宋颂, 焦 宁, 化学学报, 2019, 77, 906.) (s) Gan, X.-C.; Yin, L. CCS Chem. 2020, 2, 203. (t) Gao, X.; Xiao, Y.-L.; Zhang, S.; Wu, J.; Zhang, X. CCS Chem. 2020, 2, 1463. (u) Zhao, Q.; Isenegger, P. G.; Wilson, T. C.; Sap, J. B. I.; Guibbal, F.; Lu, L.; Gouverneur, V.; Shen, Q. CCS Chem. 2020, 2, 1921. (v) Huang, H.; Lin, H.; Wang, M.; Liao, J. Acta Chim. Sinica 2020, 78, 1229 (in Chinese). (黄浩, 林华崟, 王 敏, 廖建, 化学学报, 2020, 78, 1229.) (w) Zhang, R.; Xu, B.; Zhang, Z.; Zhang, J. Acta Chim. Sinica 2020, 78, 245 (in Chinese). (张荣华, 许冰, 张展鸣, 张俊良, 化学学报, 2020, 78, 245.) (x) Zhang, G.; Liang, Y.; Qin, T.; Xiong, T.; Liu, S.; Guan, W.; Zhang, Q. CCS Chem. 2020, 2, 1737. (y) Wu, F.-P.; Holz, J.; Yuan, Y.; Wu, X.-F. CCS Chem. 2020, 2, 2643. (z) Jiang, C.; Chen, P.; Liu, G. CCS Chem. 2020, 2, 1884.

[5] (a) Hoveyda, A. H.; Evans, D. A.; Fu, G. C. Chem. Rev. 1993, 93, 
1307. (b) Corey, E. J.; Lalic, G. Org. Lett. 2007, 9, 4921. (c) König, C. M.; Gebhardt, B.; Schleth, C.; Dauber, M.; Koert, U. Org. Lett. 2009, 11, 2728. (d) Hickmann, V.; Alcarazo, M.; Fürstner, A. J. Am. Chem. Soc. 2010, 132, 11042. (e) May, T. L.; Dabrowski, J. A.; Hoveyda, A. H. J. Am. Chem. Soc. 2011, 133, 736. (f) McDonald, R. I.; Liu, G.; Stahl, S. S. Chem. Rev. 2011, 111, 2981. (g) Dong, Z.; Ren, Z.; Thompson, S. J.; Xu, Y.; Dong, G. Chem. Rev. 2017, 117, 9333. (h) Yan, T.; Guironnet, D. Sci. Chin. Chem. 2020, 63, 755.

[6] (a) Denmark, S. E.; Almstead, N. G. Modern Carbonyl Chemistry, Ed.: Otera, J., Wiley-VCH, Weinheim, 2000, Chapter 10, p. 299. (b) Yamamoto, Y.; Asao, N. Chem. Rev. 1993, 93. 2207. (c) Kennedy, J. W. J.; Hall, D. G. Angew. Chem. Int. Ed. 2003, 42, 4732. (d) Chrétien, J.-M.; Zammattio, F.; Gauthier, D.; Grognec, E. L.; Paris, M.; Quintard, J.-P. Chem. Eur. J. 2006, 12, 6816. (e) Yamamoto, H.; Wadamoto, M. Chem. Asian J. 2007, 2, 692. (f) Yus, M.; González-Gómez, J. C.; Foubelo, F. Chem. Rev. 2011, 111, 7774.

[7] (a) Hokanson, G. C.; French, J. C. J. Org. Chem. 1985, 50, 462. (b) Shevchenko, V. P.; Myagkova, G. I.; Lazurkina, T. Y.; Dyomin, P. M.; Shrarn, S. I.; Zabolotsky, D. A.; Nagayev, I. Y.; Belosludtsev, Y. Y.; Evstigneeva, R. P.; Myasoyedov, N. F. J. Label. Compd. Radiopharm. 1989, 27, 1177. (c) Yoshida, W. Y.; Bryan, P. J.; Baker, B. J.; McClintock, J. B. J. Org. Chem. 1995, 60, 780. (d) Inoue, M.; Nakada, M. J. Am. Chem. Soc. 2007, 129, 4164. (e) Lachance, H.; Hall, D. G. Organic Reactions, Vol. 73, Eds.: Denmark, S. E. et al., John Wiley \& Sons, Inc., 2008, Chapter 1, p. 1.

[8] Huang, Y.; Huang, R.-Z.; Zhao, Y. J. Am. Chem. Soc. 2016, 138, 6571.

[9] Zhang, H.; Huang, W.; Wang, T.; Meng, F. Angew. Chem. Int. Ed. 2019, 58, 11049.

[10] Zhou, Y.; Wang, L.; Yuan, G.; Liu, S.; Sun, X.; Yuan, C.; Yang, Y.; Bian, Q.; Wang, M.; Zhong, J. Org. Lett. 2020, 22, 4532.

[11] (a) Brak, K.; Ellman, J. A. Org. Lett. 2010, 12, 2004. (b) Charest, M. G.; Siegel, D. R.; Myers, A. G. J. Am. Chem. Soc. 2005, 127, 8292. (c) Corbett, J. W.; Ko, S. S.; Rodgers, J. D.; Gearhart, L. A.; Magnus, N. A.; Bacheler, L. T.; Diamond, S.; Jeffrey, S.; Klabe, R. M.; Cordova, B. C.; Garber, S.; Logue, K.; Trainor, G. L.; Anderson, P. S.; Erickson-Viitanen, S. K. J. Med. Chem. 2000, 43, 2019.

[12] Wang, X.; Quan, M.; Xie, F.; Yang, G.; Zhang, W. Tetrahedron Lett. 2018, 59, 1573.

[13] Quan, M.; Wang, X.; Wu, L.; Gridnev, I. D.; Yang, G.; Zhang, W. Nat. Commun. 2018, 9, 2258.

[14] Lv, X.-Y.; Fan, C.; Xiao, L.-J.; Xie, J.-H.; Zhou, Q.-L. CCS Chem. 2019, 1, 328.

[15] Chen, Y.-G.; Shuai, B.; Xu, X.-T.; Li, Y.-Q.; Yang, Q.-L.; Qiu, H.; Zhang, K.; Fang, P.; Mei, T.-S. J. Am. Chem. Soc. 2019, 141, 3395.

[16] Wang, Z.-C.; Gao, J.; Cai, Y.; Ye, X.; Shi, S.-L. CCS Chem. 2021, 3, 1445.

[17] Dai, X.; Strotman, N. A.; Fu, G. C. J. Am. Chem. Soc. 2008, 130, 3302 .

[18] Lou, S.; Fu, G. C. J. Am. Chem. Soc. 2010, 132, 5010

[19] Choi, J.; Fu, G. C. J. Am. Chem. Soc. 2012, 134, 9102.

[20] (a) Organosulfur Chemistry in Asymmetric Synthesis, Eds.: Toru, T.; Bolm, C., Wiley-VCH, Weinheim, 2008. (b) Wilden, J. D. J. Chem. Res. 2010, 34, 541. (c) Chen, X.; Hussain, S.; Parveen, S.; Zhang, S.; Yang, Y.; Zhu, C. Curr. Med. Chem. 2012, 19, 3578. (d) Shah, S. S. A.; Rivera, G.; Ashfaq, M. Mini-Rev. Med. Chem. 2013, 13, 70. (e) Scozzafava, A.; Carta, F.; Supuran, C. T. Expert Opin. Ther. Patents 2013, 23, 203

[21] Choi, J.; Martín-Gago, P.; Fu, G. C. J. Am. Chem. Soc. 2014, 136, 12161

[22] Wang, Z.; Yin, H.; Fu, G. C. Nature 2018, 563, 379.

[23] Wu, L.; Yang, G.; Zhang, W. CCS Chem. 2019, 1, 623.

[24] Wang, Z.; Yang, Z.-P.; Fu, G. C. Nat. Chem. 2021, 13, 236.

[25] Tomita, D.; Wada, R.; Kanai, M.; Shibasaki, M. J. Am. Chem. Soc. 2005, 127, 4138 .

[26] Tomita, D.; Kanai, M.; Shibasaki, M. Chem. Asian. J. 2006, 1-2, 161.

[27] Lipshutz, B. H.; Pegram, J. J.; Morey, M. C. Tetrahedron Lett. 1981, 22,4603 .

[28] (a) Lin, G.-Q.; You, Q.-D.; Cheng, J.-F. Chiral Drugs: Chemistry and Biological Action, Wiley, Hoboken, NJ, 2011. (b) Chambers, R. D. Fluorine in Organic Chemistry, Blackwell, Oxford, 2004. (c) Shah, P.; Westwell, A. D. J. Enzyme Inhib. Med. Chem. 2007, 22, 527. (d) Müller, K.; Faeh, C.; Diederich, F. Science 2007, 317, 1881. (e) Lv, C.-P.; Shen, Q.-L.; Liu, D. Chin. J. Org. Chem. 2012, 32, 1380 (in Chinese). (吕翠萍, 沈其龙, 刘丹, 有机化学, 2012, 32, 1380.)
[29] Motoki, R.; Tomita, D.; Kanai, M.; Shibasaki, M. Tetrahedron Lett. 2006, 47, 8083 .

[30] Tomita, D.; Yamatsugu, K.; Kanai, M.; Shibasaki, M. J. Am. Chem Soc. 2009, 131, 6946

[31] Müller, D.; Hawner, C.; Tissot, M.; Palais, L.; Alexakis, A. Synlett 2010, $11,1694$.

[32] (a) Müller, D.; Tissot, M.; Alexakis, A. Org. Lett. 2011, 13, 3040. (b) Müller, D.; Alexakis, A. Chem. Eur. J. 2013, 19, 15226.

[33] Müller, D.; Alexakis, A. Org. Lett. 2012, 14, 1842.

[34] Cottet, P.; Müller, D.; Alexakis, A. Org. Lett. 2013, 15, 828.

[35] May, T. L.; Dabrowski, J. A.; Hoveyda, A. H. J. Am. Chem. Soc. 2011, 133, 736 .

[36] Müller, D. S.; Werner, V.; Akyol, S.; Schmalz, H.-G.; Marek, I. Org. Lett. 2017, 19, 3970.

[37] Chong, Q.; Yue, Z.; Zhang, S.; Ji, C.; Cheng, F.; Zhang, H.; Hong, X.; Meng, F. ACS Catal. 2017, 7, 5693.

[38] Mcgrath, K. P.; Hubbell, A. K.; Zhou, Y.; Santos, D. P.; Torker, S.; Romiti, F.; Hoveyda, A. H. Adv. Synth. Catal. 2020, 362, 370.

[39] (a) Trost, B. M.; Van Vranken, D. L. Chem. Rev. 1996, 96, 395. (b) Trost, B. M.; Crawley, M. L. Chem. Rev. 2003, 103, 2921. (c) Lu, Z.; Ma, S. Angew. Chem. Int. Ed. 2008, 47, 258. (d) Diéguez, M.; Pàmies, O. Acc. Chem. Res. 2010, 43, 312. (e) Weaver, J. D.; Recio, A.; Grenning, A. J.; Tunge, J. A. Chem. Rev. 2011, 111, 1846. (f) Huo, X.; Yang, G.; Liu, D.; Liu, Y.; Gridnev, I. D.; Zhang, W. Angew. Chem. Int. Ed. 2014, 53, 6776. (g) Huo, X.; He, R.; Zhang, X.; Zhang, W. J. Am. Chem. Soc. 2016, 138, 11093. (h) Tang, H.; Huo, X.; Meng, Q.; Zhang, W. Acta Chim. Sinica 2016, 74, 219 (in Chinese). (汤溟淏, 霍小红, 孟庆华, 张万斌, 化学学报, 2016, 74, 219.) (i) Huo, X.; He, R.; Fu, J.; Zhang, J.; Yang, G.; Zhang, W. J. Am. Chem. Soc. 2017, 139, 9819. (j) Huo, X.; Zhang, J.; Fu, J.; Zhang, W. J. Am. Chem. Soc. 2018, 140, 2080. (k) Zhang, M.-M.; Luo, Y.-Y.; Lu, L.-Q.; Xiao, W.-J. Acta Chim. Sinica 2018, 76, 838 (in Chinese). (张毛毛, 骆元元, 陆良秋, 肖文精, 化学学报, 2018, 76, 838.) (1) Li, Z.; Zheng, J.; Li, C.; Wu, W.; Jiang, H. Chin. J. Chem. 2019, 37, 140. (m) Wang, R.; Luan, Y.; Ye, M. Chin. J. Chem. 2019, 37, 720. (n) Yao, K.; Liu, H.; Yuan, Q.; Liu, Y.; Liu, D.; Zhang, W. Acta Chim. Sinica 2019, 77, 993 (in Chinese). (姚坤, 刘 浩, 袁乾家, 刘燕刚, 刘德龙, 张万斌, 化学学报, 2019, 77, 993.) (o) Zhang, H.-H.; Yu, S. Acta Chim. Sinica 2019, 77, 832 (in Chinese). (张洪浩, 俞寿云, 化学学报, 2019, 77, 832.) (p) Zhang, H.; Gu, Q.; You, S. Chin. J. Org. Chem. 2019, 39, 15 (in Chinese). (张 慧君, 顾庆, 游书力, 有机化学, 2019, 39, 15.) (q) Huang, L.; Cai, Y.; Zhang, H.-J.; Zheng, C.; Dai, L.-X.; You, S.-L. CCS Chem. 2019, 1, 106. (r) Wang, R.-Q.; Shen, C.; Cheng, X.; Wang, Z.-F.; Tao, H.-Y.; Dong, X.-Q.; Wang, C.-J. Chin. J. Chem. 2020, 38, 807. (s) He, R.; Huo, X.; Zhao, L.; Wang, F.; Jiang, L.; Liao, J.; Zhang, W. J. Am. Chem. Soc. 2020, 142, 8097. (t) Wang, Y.; Luo, S. Chin. J. Org. Chem. 2020, 40, 2161 (in Chinese). (王娅宁, 罗三中, 有机化学, 2020, 40, 2161.) (u) Ju, C.; Wu, Z.; Li, Y.; Zhang, W. Chin. J. Org. Chem. 2020, 40, 3925 (in Chinese). (居辰阳, 吴正兴, 李云艺, 张 万斌，有机化学，2020, 40, 3925.) (v) Li, G.; Huo, X.; Jiang, X.; Zhang, W. Chem. Soc. Rev. 2020, 49, 2060. (w) Ma, X.; Yu, J.; Wang, Z.; Zhang, Y.; Zhou, Q. Chin. J. Org. Chem. 2020, 40, 2669 (in Chinese). (马献涛, 于静, 王子龙, 张䋖, 周秋菊, 有机化学, 2020, 40, 2669.) (x) Tian, F.; Zhang, J.; Yang, W.; Deng, W. Chin. J. Org. Chem. 2020, 40, 3262 (in Chinese). (田飞, 张键, 杨武林, 邓 卫平, 有机化学, 2020, 40, 3262.) (y) Huo, X.; Zhao, L.; Luo, Y.; Wu, Y.; Sun, Y.; Li, G.; Gridneva, T.; Zhang, J.; Ye, Y.; Zhang, W. CCS Chem. 2021, 3, 1933. (z) Xiao, J.; Xu, H.; Huo, X.; Zhang, W. Ma, S. Chin. J. Chem. 2021, 39, 1958.

[40] Lee, Y.; Akiyama, K.; Gillingham, D. G.; Brown, M. K.; Hoveyda, A. H. J. Am. Chem. Soc. 2008, 130, 446.

[41] Gao, F.; Mcgrath, K. P.; Lee, Y.; Hoveyda, A. H. J. Am. Chem. Soc. 2010, 132, 14315

[42] Akiyama, K.; Gao, F.; Hoveyda, A. H. Angew. Chem. Int. Ed. 2010, $49,419$.

[43] Gao, F.; Carr, J. L.; Hoveyda, A. H. Angew. Chem. Int. Ed. 2012, 51, 6613

[44] Gao, F.; Carr, J. L.; Hoveyda, A. H. J. Am. Chem. Soc. 2014, 136, 2149.

[45] Trost, B. M.; Hung, C.-I.; Koester, D. C.; Miller, Y. Org. Lett. 2015, 17,3778 .

[46] Jin, M.; Adak, L.; Nakamura, M. J. Am. Chem. Soc. 2015, 137, 7128.

[47] (a) Hatakeyama, T.; Hashimoto, T.; Kondo, Y.; Fujiwara, Y.; Seike, H.; Takaya, H.; Tamada, Y.; Ono, T.; Nakamura, M. J. Am. Chem. Soc. 2010, 132, 10674. (b) Jin, M.; Nakamura, M. Chem. Lett. 2011, 
40, 1012. (c) Hatakeyama, T.; Fujiwara, Y.; Okada, Y.; Itoh, T.; Hashimoto, T.; Kawamura, S.; Ogata, K.; Takaya, H.; Nakamura, M. Chem. Lett. 2011, 40, 1030.

[48] (a) Adams, C. J.; Bedford, R. B.; Carter, E.; Gower, N. J.; Haddow, M. F.; Harvey, J. N.; Huwe, M.; Cartes, M. Á.; Mansell, S. M.; Mendoza, C.; Murphy, D. M.; Neeve, E. C.; Nunn, J. J. Am. Chem.
Soc. 2012, 134, 10333. (b) Bedford, R. B.; Brenner, P. B.; Carter, E; Clifton, J.; Cogswell, P. M.; Gower, N. J.; Haddow, M. F.; Harvey, J. N.; Kehl, J. A.; Murphy, D. M.; Neeve, E. C.; Neidig, M. L.; Nunn, J.; Snyder, B. E. R.; Taylor, J. Organometallics 2014, 33, 5767.

[49] Evans, D. A.; Aye, Y. J. Am. Chem. Soc. 2006, 128, 11034.

(Cheng, B.) 